\title{
Species Uptake and Mass Transport in Membranes for Vanadium Redox Flow Batteries
}

\author{
Ramez A. Elgammal ${ }^{1}$, Zhijiang Tang ${ }^{1,2}$, Che-Nan Sun ${ }^{2}$, Jamie Lawton ${ }^{1}$ and Thomas A. \\ Zawodzinski Jr. ${ }^{1,2}$ \\ ${ }^{1}$ Department of Chemical and Biomolecular Engineering, University of Tennessee at \\ Knoxville, Knoxville, Tennessee 37996 \\ ${ }^{2}$ Materials Science and Technology Division, Oak Ridge National Laboratory, Oak \\ Ridge, Tennessee 37831
}

\begin{abstract}
In this contribution, we provide a synthesis of results to date describing uptake and mass transport of water, vanadium species and protons in Nafion membranes for use as separators in VRFBs. Resistance issues as well as species cross-over are important contributors to performance loss in VRFBs. After a brief discussion of our state-of-theart cell performance, we consider the uptake and transport of various species through a number of membrane materials. We draw together numerous previous studies and augment them with new data to provide a summary of our present state of understanding of the experimental facts regarding membrane behavior.
\end{abstract}

\section{Introduction}

Over the past several years, there has been significant improvement in many characteristics of VRFBs. The overall rate at which redox flow batteries can be operated with good efficiency has been substantially increased. The work of the PNNL group has improved the temperature and concentration range of stability of electrolytes. $[1,2]$ This has been undergirded by detailed studies of many aspects of the components and devices, ranging from some first attempts to assess factors leading to durability or capacity fade to

(C) 2017. This manuscript version is made available under the Elsevier user license http://www.elsevier.com/open-access/userlicense/1.0/ 
detailed studies of electrode kinetics to systematic investigations of water, acid and vanadium species uptake into membranes. Many of these studies have been reported for different cell designs, electrode materials and membrane types.

Redox flow batteries are a type of 'open battery' unlike the normal type of battery. Reagents flow in and out of the battery and contact electrodes. From that simple notion stem some important aspects of the structure of these batteries. In a normal battery, the layered electrodes and separator are wound to pack in high area per volume. The emphasis is strongly on achieving high energy density. For an open system, the manifolding and flow in a wound system is impractical and the common geometry is a stack of flat plate. To achieve high performance in this configuration requires higher power density and higher current density of operation. In the traditional battery, an operating current density in the $\mathrm{mA} / \mathrm{cm}^{2}$ range and an areal specific resistance (ASR) on the order of $10 \mathrm{ohm} \mathrm{cm}^{2}$ are typical. For the open system, this is not acceptable if we are to overcome the disadvantage of not being able to wind the components. In early work, ASR values for VRFBs were indeed rather high. [3]. Based on this, we focus on achieving much lower cell resistance and higher current density, both by orders of magnitude. We have shown that we must use thin membranes for the highest performance. By comparison to numbers given above, the ASR is $\sim 0.05 \mathrm{ohm} \mathrm{cm}^{2}$ or less in a well-hydrated PEM fuel cell using membranes analogous to those in our flow battery. This allows us to significantly (and linearly) decrease resistance in the cell, at the expense of the possibility of increased 'cross-over' of redox active vanadium species, an important mechanism of capacity loss with repeated cycling or of lower than desired coulombic efficiency in a battery. 
A complete description of the transport of all species is quite complex. The membrane is exposed to concentrated acid solutions containing similar, though lower, concentrations of vanadium species in four different oxidation states, the relative amounts of which vary with state of charge of the battery. Under these situations, it is entirely expected that the transport of any one of the species present (protons, water, up to 4 vanadium cations, 'membrane' and bisulfate) will be significantly coupled to that of the others. This implies that a 'concentrated solution theory' (CST) approach must be embraced.[4, 5] One of our goals has been to collect sufficient data to understand the possibilities for simplification of the monstrously complex description demanded by CST. Another part of our work has been to use observations under dilute solution conditions to provide some initial guidance to behavior, perhaps exhibiting some limiting aspects. We now outline the background behind some specific aspects of these studies.

\section{Membrane conductivity}

The membrane electrolyte or separator used plays a key role in this cell resistance. As noted above, membrane conductivity plays a major role in determining the overall performance. The conductivity is itself strongly dependent on the composition within the membrane. In membranes exposed to dilute electrolytes, typically below $\sim 0.2 \mathrm{M}$, little or no electrolyte is taken into the membrane and the composition of the membrane is dominated by partitioning effects - exchange of $\mathrm{H}^{+}$for vanadium cations as external solution composition changes-- and minor changes in water content due to lower water activity in contact with the membrane.

When membranes are exposed to concentrated electrolytes, the exclusion of co-ions expected from the Donnan equilibrium is no longer broadly operative. Electrolyte taken 
up by the membrane can alter the ionic equilibrium within membrane and further influence its ionic transport properties, such as conductivity and ion permeation, as well as water transport. The conductivity of cation exchange membrane, such as Nafion, is determined by its contents of electrolyte species. However, due to the complexity of ionic transport within ion exchange membrane under strong electrolyte equilibrium, very limited understanding has been established related to the fundamental mechanisms of ion transport in this scenario.

Some preliminary studies of acid-membrane interaction on membrane performance have been carried out for polymer electrolyte fuel cell study. Nafion equilibrated with sulfuric acid solution has been studied by several research groups.[6-8] In the high acid concentration range studied, sulfuric acid can effectively break through the Donnan potential caused by sulfonate in membrane. The partitioned sulfuric acid can alter the ionic environment in Nafion and enhance its conductivity at low concentrations. Equilibration of Nafion with concentrated acid solutions also reduces its water content a critical facilitator of proton transport in IEMs[9]. The observed conductivity reflects a trade-off between the additional charge carriers and the dehydration effect, with the latter ultimately controlling behavior at concentrations much above $1 \mathrm{M}$.

The transport number of the anion in Nafion was measured to be less 0.1 within the studied acid concentration range, since the diffusivity of anions is more than one order of magnitude lower than that of protons in membrane. Hydrohalogenic and phosphoric acids have also been used in acid-membrane equilibration studies. The measured partitioning coefficients of $\mathrm{HF}, \mathrm{HCl}$ and $\mathrm{HBr}$ were higher than sulfuric acid, and in the sequence of $\mathrm{HF}>\mathrm{HBr}>\mathrm{HCl}[10]$. It was found that $\mathrm{HF}$ and phosphoric acid has very limited influence 
on membrane conductivity[11]. Kusoglu et al. carried out a more detailed study on Nafion equilibrated with $\mathrm{HBr}$ for hydrogen-bromine redox flow battery[12]. Small angle X-ray scattering was carried out to obtain morphological information and correlated to the ionic equilibrium and conductivity of membrane.

The presence of vanadium cations in the membrane is another important factor affecting membrane conductivity. Due to the differences in fundamental transport mechanism, the mobility of cations, $\sim 10^{-8} \mathrm{~m}^{2} \mathrm{~V}^{-1} \mathrm{~s}^{-1}$, is generally at least one order of magnitude slower than that of protons $\left(\mathrm{u}_{\mathrm{H}+} \cong 10^{-7} \mathrm{~m}^{2} \mathrm{~V}^{-1} \mathrm{~s}^{-1}\right)$ in fully hydrated Nafion[11, 13]. In a VRFB, vanadium cations can actively partition into the membrane to replace fast moving protons and reduce conductivity. Cho et al. [14] reported the vanadium partitioning isotherm in Nafion soaked in vanadium/acid mixed solution of different valence states, as well as membrane's conductivity after ion exchange. Conductivities of 20 to $30 \mathrm{mS} \mathrm{cm}^{-1}$ were estimated on Nafion 212 membrane with $21 \% \mathrm{~V}^{3+}$ and $12 \% \mathrm{VO}^{2+}$ content. It has been shown that the Nafion membrane has a stronger affinity to multivalent cations than to protons and other monovalent cations[15-17]. Because some metal cations can reduce the water content in Nafion from its fully hydrated state, they can potentially impede proton motion via this mechanism as well. Additionally, some transition metal cations can directly interact with the proton to alter its mobility and thereby further influence membrane conductivity via an unclear mechanism[15]. This seems to be the case for vanadium oxo-anions, as discussed below. In the work that follows, we provide indications of this phenomenon via analysis of conductivity behavior of vanadium/proton systems, comparing multivalent species with and without oxofunctionality partitioning into the membrane in dilute systems. If the dilute system 
behavior prevailed, the large impact on conductivity of partitioning of vanadium into the membrane would dramatically limit VRFB performance. We then discuss the rather different behavior of the concentrated systems typically used in practical battery electrolytes.

\section{Vanadium 'cross-over'}

Another line of recent research focuses on understanding and modeling the transport properties of vanadium ions in the environment of the VRFB to understand and control cross-over of vanadium species. Measurements of crossover in a novel operating VRFB cell involving three flow regions show increased mobility of vanadium ions on the positive side through the membrane in the direction concurrent with the flux of protons. Crossover against the proton flux was reduced from the static state by $75 \%$. However, the patterns of which ion species diffused and why suggested trends depending on ion concentrations at varying SOC, such as increased transport of $\mathrm{VO}_{2}{ }^{+}$at high current densities, when that ion would be increasingly present in the solution.[18]

A discrepancy exists across a number of studies regarding on which side of the battery the vanadium tends to accumulate over the course of many cycles. Two different models suggest an expected build-up of vanadium in the negative reservoir. [19, 20] Meanwhile, two experimental reports describe an overall vanadium accumulation on the positive side. [21, 22]

The modeling work of Knehr et al[19] is paired with experimental cycling data that shows a decrease in capacity over 45 cycles. The shorter charge time is attributed to vanadium imbalance in the electrolyte reservoirs. A model based on convection, diffusion and migration indicates the net accumulation of vanadium in the negative reservoir, but 
this is highly dependent on the viscosity values used as input in the model. There is limited data in the literature reporting on the viscosity of the negative electrolytes, particularly involving $\mathrm{V}^{2+}$. The authors used viscosity values reported elsewhere $(2.5 \mathrm{cP})$, but the values from this measurement are in 1.5- $2 \mathrm{M}$ sulfuric acid, vs. 5M sulfuric acid used in the model. The value used as input for the viscosity of the positive electrolyte (1M Vanadium, $5 \mathrm{M}$ sulfuric acid) was $5 \mathrm{cP}$. This was based on a handful of reports that measured viscosity of $1 \mathrm{M} \mathrm{VO}^{2+}$ in $3 \mathrm{M} \mathrm{H}_{2} \mathrm{SO}_{4}$ at $\sim 5 \mathrm{cP}, 1 \mathrm{M} \mathrm{VO}_{2}{ }^{+}$in $5 \mathrm{M} \mathrm{H}_{2} \mathrm{SO}_{4}$ at $5 \mathrm{cP}$, and $\mathrm{VO}^{2+}$ and $\mathrm{VO}_{2}^{+}$in $5 \mathrm{M} \mathrm{H}_{2} \mathrm{SO}_{4}$ at $\sim 9$ and $8 \mathrm{cP}$ respectively. The vanadium concentration in the latter values, however, is not clear from the report. Meanwhile, other reports show values for $2 \mathrm{M} \mathrm{VO}^{2+}$ and $2 \mathrm{M} \mathrm{H}_{2} \mathrm{SO}_{4}$ at $2.69 \mathrm{cP}[23], 2.11 \mathrm{cP}[24]$, and $2.79 \mathrm{cP}$ [25]. Viscosity of $2 \mathrm{M} \mathrm{VO}^{2+}$ in $5 \mathrm{M} \mathrm{H}_{2} \mathrm{SO}_{4}$ have been reported at $\sim 5 \mathrm{cP}[26]$ and $5.169 \mathrm{cP}[27]$ and values of $1 \mathrm{M} \mathrm{VO}^{2+}$ and $5 \mathrm{M} \mathrm{H}_{2} \mathrm{SO}_{4}$ at $3.37 \mathrm{cP}[28]$. The authors of this study did not address the discrepancy between the model and experimental data, though they did refer to two earlier modeling studies that resulted in the opposite conclusion. Of those two references, one[27] is a thermal model of the battery and does not address cross over, and the other[28] used a selemion membrane, which in a previous report was shown to result in the opposite trend to that Nafion showed (i.e. vanadium build up on the positive rather than negative side)[20]. The modeling work comparing anion and cation exchange selemion membranes to Nafion [21] results in vanadium accumulation in the positive reservoir, while the model suggests the opposite trend for the Nafion membrane, mainly as a result of higher diffusivity rates for vanadium ions in Nafion than the other membranes. 
The first of the two experimental studies that suggested vanadium build up on the positive side of the battery over time monitored the concentrations of different ions in the electrolytes over cycling time using an automated titration instrument.[21] Interestingly, during self-discharge, vanadium accumulated on the negative side beginning at both $0 \%$ SOC and $65 \%$ SOC. In the case of monitoring crossover at $0 \%$ SOC where $\mathrm{V}^{3+}$ crossed against $\mathrm{VO}^{2+}$ over 90 hours $\sim 13$ moles of $\mathrm{VO}^{2+}$ crossed verses $\sim 7$ moles of $\mathrm{V}^{3+}$ which suggests a 3:2 crossover ratio, maintaining charge balance, which indicates an interdependence of the diffusion crossover of the two ions. During charge cycles, the overall accumulation of vanadium was on positive side and over 250 cycles, the amount of vanadium on the positive side increased by $35 \%$. Tang et al. suggested that the reason for the difference here could be that Sun et al. only charged to $65 \%$ SOC and thereby avoided electrode gas reactions that occur at SOC above $90 \%$. The second experimentally based report that observed the net accumulation of vanadium in the positive reservoir charged up to a SOC of $90 \%[29]$ However this experiment used iron ions counter to the vanadium ions, which could alter the crossover and used $\mathrm{HCl}$ instead of $\mathrm{H}_{2} \mathrm{SO}_{4}$ in the electrolyte, which could change the swelling patterns of the membrane in comparison to other studies.

In this contribution, we provide a synthesis of results to date and some new results describing uptake and mass transport of water, vanadium species and protons in Nafion membranes for use as separators in VRFBs. Nafion membranes were chosen as a benchmark because of the extensive literature on these membranes. Nonetheless, is important to emphasize that Nafion membrane preparation has changed over time as a shift was made between cast and extruded membrane production occurred [30]. Since the 
experimental studies on this membrane form the backbone of earlier studies, continuing to use this benchmark also allows us to build the most extensive database of RFB-specific properties available. It is important to note that in our work and work throughout the field, new membranes are being studied in this application space all the time, including work on various hydrocarbon polymer-based membranes, new materials such as composites and conventional membranes subjected to different pretreatments. [31]. The latter approach focuses on accessing different membrane morphology and thus uptake and transport characteristics by using, for example, thermal treatments. [9] The field takes its cue from the fuel cell membrane approaches and thus supported membranes are also of interest. Again, swelling control can be accessed in this context.

Resistance issues as well as species cross-over are important contributors to performance loss in VRFBs. After a brief discussion of our state-of-the-art cell performance employing thin membranes, we consider the uptake and transport of various species through membrane materials under various conditions. We draw together numerous previous studies and augment them with new data to provide a summary of our present state of understanding of the experimental facts regarding membrane behavior. From there, we compare rates of various processes and then sum up some expectations for transport in the membrane.

\section{Experimental}

\subsection{Polarization Curve}

Raw vanadium electrolyte solutions were prepared by dissolving vanadium(IV) sulfate oxide hydrate (99.9\%, Alfa Aesar) into diluted sulfuric acid. $1.7 \mathrm{M} \mathrm{VO}_{2}^{+}$and 1.7 
$\mathrm{M} \mathrm{V}^{2+}$ in $5 \mathrm{M}$ total sulfate solution were prepared by two-step electrochemically charging reported elsewhere[29]. Battery testing was conducted using a zero-gap cell configuration. A $5 \mathrm{~cm}^{2}$ single cell (Fuel Cell Technologies) hardware consisted of aluminum end plates, gold-plated current collectors, and graphite blocks with a single serpentine flow field for electrolyte distribution. Multiple sheets of experimental grade carbon paper were stacked at each side and served as the electrode of the battery. A single piece membrane was used as the separator for the battery. Prior to the polarization measurement, the cell was conditioned by sequentially charging and discharging at 200 $\mathrm{mA} / \mathrm{cm}^{2}$ for several $10 \mathrm{~min}$ steps. The discharge polarization curve measurement was performed using a Bio-Logic potentiostat coupled with a 20A booster. An applied voltage was held for 10 seconds to develop a steady state current followed by impedance spectroscopy over the frequency range from $5 \mathrm{kHz}$ to $1 \mathrm{kHz}$ for measuring high frequency resistance (HFR). The solution in each compartment of the individual electrodes was not recirculated. Instead, the outlet from each electrode was directed to a separate outlet bottle. This operation mode is referred to as "single pass" and allows us to maintain a controlled state of charge at each operating current. A constant flow rate of $90 \mathrm{~mL} / \mathrm{min}$ was maintained with a 2 channel peristaltic pump. The battery and the solution bottles were installed in an environmental chamber set at $30^{\circ} \mathrm{C}$. Each electrolyte storage bottle was blanketed with flow of ultra-high purity nitrogen.

\subsubsection{Electrolyte equilibrium characterization and conductivity measurement}

Nafion membranes purchased from Ion Power Inc. were pretreated, equilibrated and characterized using a standard procedure from the literature[33]. The DI water (18.2 $\mathrm{M} \Omega \cdot \mathrm{cm}$ ) used in this study was generated by MilliQ water purification system. Pretreated 
membrane sample was stored in DI water before use. Other membranes mentioned were similarly treated. For all measurements, membranes were equilibrated with the appropriate bathing solutions for at least 3 days. These procedures are described in detail in references 33 and 35 .

Electrolyte solutions of two concentrations were prepared to achieve different membrane-electrolyte equilibriums. The dilute $\mathrm{VCl}_{3} / \mathrm{HCl}$ solutions were prepared from $\mathrm{VCl}_{3}$ powder $\left(99 \%\right.$, Sigma Aldrich) and $\mathrm{HCl}\left(1 \mathrm{~mol} \cdot \mathrm{dm}^{-3}\right.$, Alfa Aesar). The total chloride concentration in solutions was controlled at $0.1 \mathrm{~mol} \mathrm{dm}^{-3}$ to prevent chloride entering micropores in the membrane, according to Donnan exclusion. More concentrated electrolyte solutions were prepared to achieve equilibrium including co-ions in the membrane ionic domains. The raw electrolyte solution containing $2 \mathrm{~mol} \mathrm{dm}^{-3} \mathrm{VOSO}_{4}$ and 3 mol dm ${ }^{-3} \mathrm{H}_{2} \mathrm{SO}_{4}$ was made from $\mathrm{VOSO}_{4} \cdot x \mathrm{H}_{2} \mathrm{O}\left(99.9 \%\right.$ Alfa Aesar) and $\mathrm{H}_{2} \mathrm{SO}_{4}(96 \%$, Alfa Aesar). Electrolyte solutions containing $2 \mathrm{~mol} \cdot \mathrm{dm}^{-3} \mathrm{~V}^{3+}$ or $\mathrm{VO}_{2}^{+}$were made by electrolysis from the raw electrolyte. Electrolyte solutions with $2 \mathrm{~mol} \mathrm{dm}{ }^{-3} \mathrm{~V}^{\mathrm{x}+}\left(\mathrm{V}^{3+}\right.$, $\mathrm{VO}^{2+}$ or $\mathrm{VO}_{2}^{+}$) were diluted by $5 \mathrm{~mol} \mathrm{dm}^{-3} \mathrm{H}_{2} \mathrm{SO}_{4}$ to make solutions with $0.25,0.50,0.75$, $1.00,1.25,1.50$ and $1.75 \mathrm{~mol} \mathrm{dm}^{-3}$ vanadium and $5 \mathrm{~mol} \mathrm{dm}^{-3}$ total sulfate or bisulfate.

\subsection{Permeability measurements}

Two different and complementary methods have been used to probe vanadium ion cross-over through the membrane. A Magnettech Miniscope EPR (Berlin, Germany) was used to monitor concentration changes of vanadyl ion for permeability measurements. The cell hardware used for ion permeability in this study was battery cell hardware purchased from Fuel Cell Technologies. The temperature of the cell was controlled by cartridge heaters. $20 \mathrm{~mL}$ Vanadium ion solutions on one side of the membrane and $20 \mathrm{~mL}$ 
of a blank acid solution on the counter side were flowed through a flow field in the graphite plates. The blank solution was additionally flowed through a Teflon capillary held in the center of the EPR cavity. The solutions were pumped using a Masterflex L/S four channel peristaltic pump system at $25 \mathrm{~mL} / \mathrm{min}$. The membrane used was a Nafion 117 membrane pretreated by heating to $75^{\circ} \mathrm{C}$ for 1 hour in $3 \%$ hydrogen peroxide followed by 1 hour in deionized water, 1 hour in $0.5 \mathrm{M}$ sulfuric acid, and 1 hour in deionized water. The active area of the membrane was $5 \mathrm{~cm}^{2}$. Teflon gaskets were used to create a 1 mil pooling area for the solutions inside the cell.

For the experiments measuring the dependence of permeability on temperature, varying concentrations (0.1-.4M) of vanadyl sulfate (Alfa Aesar, 99.9\%) were dissolved in varying concentrations $(0.5-2 \mathrm{M})$ of sulfuric acid. The ratio concentration of sulfuric acid to vanadyl sulfate was maintained at 5:1. Between crossover measurements the cell and tubing was thoroughly rinsed with DI water. For the experiments monitoring the effects of maintaining a constant cation concentration, the cation concentration is the sum of twice the concentration of $\mathrm{VO}^{2+}$ plus the concentration of sulfuric acid. Due to the common ion effect, the second proton on the sulfuric acid is not expected to significantly dissociate.

In other experiments, permeability of vanadium ions through Nafion was measured in a Permegear counter diffusion cell at $30{ }^{\circ} \mathrm{C}$. For example, on the rich side of the cell, the solution contained $1 \mathrm{~mol} \cdot \mathrm{dm}^{-3} \mathrm{VOSO}_{4}$ and $4 \mathrm{~mol} \mathrm{dm}^{-3} \mathrm{H}_{2} \mathrm{SO}_{4}$ and on the receiving side $5 \mathrm{~mol} \mathrm{dm}^{-3} \mathrm{H}_{2} \mathrm{SO}_{4}$ was used. The $\mathrm{VO}^{2+}$ concentration on the receiving side was monitored by circulating the solution through a UV-Vis flow cell coupled with an ALS-Japan SEC 2000 portable UV-Vis spectrometer. The temperature of the system was 
maintained by water circulation in the water jacket of the diffusion cells with a refrigeration water circulator (Fisher Scientific Isotemp 3016D). During the measurement, the solutions were mixed by magnetic stirrers to minimize the influence of vanadium distribution on membrane surface. The volume of each cell chamber is $50 \mathrm{~mL}$. The concentration of $\mathrm{VO}^{2+}$ in the receiving side can be calculated by Beer-Lambert law. The $\mathrm{VO}^{2+}$ mass balance in this measurement can also be expressed as $V \frac{d c_{\text {receiving }}}{d t}=$ $P A\left(\frac{c_{\text {giving }}-c_{\text {receiving }}}{\delta}\right)$, where the diffusivity of $\mathrm{VO}^{2+}$ across membrane $P$ was calculated from $P=-\frac{V \delta}{2 A t} \ln \left(\frac{c_{\text {giving }}^{t=0}-2 c_{\text {receiving }}^{t}}{c_{\text {giving }}^{t=0}}\right) V$ is the volume of solution on either side of the battery; $A$ is the cross sectional area of the diffusion cell; $\delta$ is the thickness of the membrane; $t$ is time the solution is allowed to equilibrate. $\mathrm{V}^{3+}$ diffusivity in Nafion was measured by a similar means. The solution was generated electrochemically.

\section{Results and discussion}

\subsection{High-performance VRBs}

In Figure 1, we present polarization curves showing recently obtained levels of performance starting with electrolyte at $\sim 100 \%$ state of charge. These results significantly surpass previously reported data $[32,34]$. Using SDAPP 2.3 as a membrane gave a peak power density of $2588 \mathrm{~mW} \mathrm{~cm}^{-2}$ and a limiting current density of $5033 \mathrm{~mA}$ $\mathrm{cm}^{-2}$ compared to Nafion 212's performance of $1355 \mathrm{~mW} \mathrm{~cm}^{-2}$ at a limiting current density of $1817 \mathrm{~mA} \mathrm{~cm}^{-2}$, both of which vastly exceeded the performance described in the references cited above. To emphasize the significance of the membrane-related loss in this work, we note that the ohmic loss from the membrane at peak power $\left(\sim 3.4 \mathrm{~A} \mathrm{~cm}^{-2}\right.$ at $0.8 \mathrm{~V}$ ) is roughly $440 \mathrm{mV}$ out of the total loss of $0.8 \mathrm{~V}$ relative open circuit. The ASR is 
roughly $20 \%$ of that expected from Nafion 117 , for example. If we could draw this current density from a cell using Nafion 117, over $2 \mathrm{~V}$ of loss would be expected. We note that these results were obtained in a small cell designed to highlight the contributions of material properties to cell losses.

$i R$-free polarization curves represent a combination of activation and concentration polarizations, which are primarily attributed to the electrode kinetics and mass transport through the electrode induced by the flow field, respectively.

We attribute the superior performance of SDAPP over Nafion 212 to higher selectivity of the membrane, i.e. a higher ratio of conductivity to permeability $[35,36]$. Improved electrode properties along with a concentrated electrolyte $\left(1.7 \mathrm{M} \mathrm{V}^{\mathrm{x}+} / 3.3 \mathrm{M}\right.$ $\mathrm{H}_{2} \mathrm{SO}_{4}$ ) at high flow rate minimize the losses due to kinetic and electro-active reagent mass transport processes. The cell voltage therefore shows a linear behavior as a function of current density. A system with that level of performance is amenable to cycling with $90 \%$ efficiency at $500 \mathrm{~mA} \mathrm{~cm}^{-2}$ or more. The cycling accesses lower states of charge and thus the actual cycling performance is not reflected by the polarization curve. However, such curves indicate the intrinsic, best case losses due to cell resistance, kinetic limitations and mass transport resistances in the cell. As can be seen in Figure 1, the essentially ohmic appearance of the polarization curves indicated that the latter are minimal. With a measured ASR of $0.13 \mathrm{ohm} \mathrm{cm}^{2}$, the IR corrected curve still shows some ohmic character. This is due to the ohmic loss associated with delivery of reagents through the pores of the electrode.

Therefore, to a first approximation, the slope of the iR-free curve shown in Figure 1 represents the ASR for ionic conduction in the electrode, consistent with AC impedance 
results. With the benefit of the constant OCV VRFB system given by the single pass mode, we are able to estimate the length of ionic pathway in the electrode according to Equation (1):

$$
A S R=\frac{l}{\sigma_{e}} \times N_{m}
$$

where $l$ is the membrane thickness, $\sigma_{e}$ is the electrolyte conductivity, and $N_{m}$ is the MacMullin number. The calculated path length is $1.01 \mathrm{~mm}$, which represents the total conduction length for both electrodes including the tortuosity factor. If we assume that the loss due to the ionic conduction in the electrode is symmetric for positive and negative electrode, the conduction length for each side would be $505 \mu \mathrm{m}$. The thickness of the electrode (t) is approximately $310 \mu \mathrm{m}$ in the cell with $20 \%$ compression. This result suggests that the reaction zone is geometrically toward the membrane side. While the calculated conduction length is greater than the electrode thickness, this may be attributed to tortuosity and perhaps minor transport losses within the electrode. This finding is opposed to previous studies, which suggest the reaction zone is closer to the current collector. In the higher performance cells used here different carbon electrode properties and the higher vanadium concentration electrolyte fed at $100 \%$ SoC in a single pass manner facilitate the mass transport of the active species and therefore move the reaction zone.

\subsection{Influence of vanadium cations on ion transport in the polymer membrane: Dilute}

\section{Solution Case}

While it is well known that the conductivity of Nafion decreases dramatically due to prolonged exposure to acidic electrolyte solutions and that battery and efficiency losses 
may be attributed in part due to vanadium permeation across the membrane, much less is known about the equilibrium between Nafion and ionic solutions and its impact on proton transport. In general, multivalent cations are preferentially partitioned into Nafion compared to protons due to a larger electrostatic interaction and stronger binding energy with the negatively charged sulfonic acid group.[15, 33, 37] Although it has been demonstrated that factors other than valence, e.g. ionic size, can influence the cation partitioning competition in Nafion, valence state generally favors uptake of multivalent cations over monovalent cations.[17, 38] The solvation shell may play a role in screening the electrostatic interactions with sulfonic acid sites. In order to determine how these effects manifest in a VRB membrane environment, we have examined how uptake and conductivity are influenced in both the case of dilute and concentrated solutions.

In dilute solutions, the relative content of $\mathrm{V}^{3+}$ and $\mathrm{VO}^{2+}$ in the membrane trend closely in magnitude with respect to the relative vanadium content in solution the phase. These data are shown in Figure 2. The partitioning of $\mathrm{V}^{3+}$ into the membrane is only slightly stronger than $\mathrm{VO}^{2+}$, despite $\mathrm{V}^{3+}$ having a higher ionic charge than $\mathrm{VO}^{2+}$. (Note that the 'normalized' $\mathrm{x}$-axis presents solution concentration as the mole fraction of vanadium in the proton/vanadium bathing mixture and the normalized y-axis presents the membrane concentration as the fraction of sulfonate sites 'occupied' by vanadium.) Perhaps the relatively small difference is due to the fact that $\mathrm{V}^{3+}$ has a more strongly held and saturated first hydration shell than does $\mathrm{VO}^{2+}$, leading to more effective screening of charge (see below).

Also shown in Figure 2 is the effect that vanadium speciation in Nafion has on water content $\lambda=n_{\mathrm{H}_{2} \mathrm{O}} / n_{-\mathrm{SO}_{3} \mathrm{H}}$. Both $\mathrm{V}^{3+}$ and $\mathrm{VO}^{2+}$ have high affinity for sulfonate in the 
membrane, but surprisingly they do not significantly reduce membrane water content.[33] This is contradictory to other reported observations that water content loss is in accord with cation affinity to membrane.[15, 16] In those cases, tight ion pairing between ions and sulfonate sites leads to a diminished affinity for water. Our results suggest that cationic affinity to membrane is not the only dominating factor in determining water uptake of the membrane in the cation form. The highly hydrated vanadium cations themselves carry additional water into the membrane and the results would then indicate that it is likely that only solvent-separated ion-pairs form.[39]

In the dilute electrolyte case the membrane is in the form $\mathrm{H}^{+} / \mathrm{V}^{\mathrm{x}}$. The conductivity loss by $\mathrm{VO}^{2+}$ partitioning into Nafion has been studied in detail and it was shown that $\mathrm{VO}^{2+}$ strongly hinders proton motion and effectively lowers the proton concentration in the membrane.[33] The loss of conductivity due to $\mathrm{V}^{3+}$ is less pronounced than with $\mathrm{VO}^{2+}$ as shown in Figure 3(a). The interaction of $\mathrm{VO}^{2+}$ and $\mathrm{V}^{3+}$ with the membrane is thus likely different, leading to differing effects on proton mobilities. Overall, the membrane conductivity decreases by more than an order of magnitude as protons are replaced by vanadium ions.

Losses in conductivity could be caused by caused by lowered proton concentration and/or reduced proton mobility. The conductivity of membranes equilibrated in solutions of $\mathrm{V}^{3+}$ is given by:

$$
\sigma_{m_{V 3+}}=F\left(z_{H^{+}} c_{H^{+}} u_{H^{+}}+z_{V^{3+}} C_{V^{3+}} u_{V^{3+}}\right)
$$


where $F$ is Faraday's constant, $z$ is charge number, $c$ is the concentration in the membrane phase and $u$ the mobility. Equation (2) may be simplified by introducing a normalized content fraction $x_{M}=z_{M} c_{M} / c_{-\mathrm{SO}_{3} \mathrm{H}}$ giving:

$$
\sigma_{m_{V 3+}}=F c_{-\mathrm{SO}_{3} \mathrm{H}}\left(x_{H^{+}} u_{H^{+}}+x_{V^{3+}} u_{V^{3+}}\right)
$$

where $\mathrm{C}_{\mathrm{SO}_{3} \mathrm{H}^{-}}$is calculated from the density measurement of fully hydrated proton-form Nafion and is assumed to be invariant of vanadium content. Equation (3) thus gives a simple means to calculate proton and $\mathrm{V}^{3+}$ mobilities from membrane uptake and conductivity measurements and these results are summarized in Table 1.

In Figure 3(b) we show the membrane conductivity's dependence on vanadium uptake. A model was constructed to fit the data, which assumed that: 1) the mobilities of the vanadium ions were constant, 2) $\mathrm{H}^{+}$mobility is linearly reduced by $\mathrm{VO}^{2+}$ abundance, and 3) $\mathrm{H}^{+}$has constant mobility in coexistence with $\mathrm{V}^{3+}$. By calculation, $\mathrm{V}^{3+}$ and $\mathrm{VO}^{2+}$ both have much lower mobility than protons in proton form Nafion. As we can see here, in $\mathrm{H}^{+} / \mathrm{V}^{3+}$ form membrane, conductivity is linearly decreased with increasing $\mathrm{V}^{3+}$ content in membrane. This implies that both proton and $\mathrm{V}^{3+}$ have essentially constant mobility within the entire vanadium content range. For $\mathrm{VO}^{2+}$, the conductivity is obviously lower than that predicted for the constant mobility of both ions. Accordingly, we assume proton mobility is linearly decreased by $\left[\mathrm{VO}^{2+}\right]$ in membrane. It turned out that membrane conductivity matches reasonable well with the linear proton mobility assumption. The changing proton mobility with $\mathrm{VO}^{2+}$ suggests there is an interaction between protons and $\mathrm{VO}^{2+}$

The structure of hydration shells and the complexation chemistry of vanadium ions is of great interest to clarify the behavior of $\mathrm{V}^{3+}$ and $\mathrm{VO}^{2+}$ exchanged Nafion and the 
apparent $\mathrm{VO}^{2+}$ effect on proton transport in the membrane.[39, 40] Considerations of the structure and chemistry of the vanadium oxo species in particular have been presented. Based on classic work by Ballhausen and Gray [41], Winkler and Gray [42] gave an excellent and useful overview on the vanadyl cation in the context of a more general discussion of metal oxo complexes. The V-O bond is exceptionally strong. One important takeaway from the latter is that the $\mathrm{V}-\mathrm{O}$ bond includes significant back bonding contributions rendering the oxygen quite weakly basic. They report that the primary electronic band observed for this species is unchanged between $\mathrm{pH}-0.5$ to 1.5 . Vijayakumar et al. [43] presented a detailed discussion of the proposed interaction between $\mathrm{VO}\left(\mathrm{H}_{2} \mathrm{O}\right)_{5}{ }^{2+}$ and the sulfonate of Nafion. They presented several structures that were probed using electronic structure calculations and EXAFS at vanadium and sulfur edges. However, the spectra predicted did not present good matches. Moreover, the specific interactions proposed in that work, in which sulfonate enters the vanadyl primary solvation sphere seem unlikely in light of the similar mobility of this cation relative to that of $\mathrm{V}\left(\mathrm{H}_{2} \mathrm{O}\right)_{6}{ }^{3+}$ which we surmise from conductivity and permeability data.

Based on this, we conclude that the reason for the different cation-proton interactions has not been satisfactorily explained yet. One simple hypothesis that we find plausible is the possibility of protonation of the oxo moiety on the vanadium but the argument for that seems to be weakened by the comments of Winkler and Gray.

It has been demonstrated that high valence cations, like $\mathrm{Al}^{3+}$, can form stable hydration shells beyond the first hydration shell by H-bonding.[44-46] Cations with higher valence can have more ordered hydration shells and stronger restriction on water molecules in hydration shell. Water in the hydration shells of the multivalent cation is 
more condensed than in bulk water.[47] $\mathrm{V}\left(\mathrm{H}_{2} \mathrm{O}\right)_{6}^{3+}$ has a water self-exchange rate constant of about $5 \times 10^{2} \mathrm{~s}^{-1}$ and $\mathrm{VO}\left(\mathrm{H}_{2} \mathrm{O}\right)_{5}^{2+}$ has self-exchange rate constants of $5 \times 10^{2} \mathrm{~s}^{-1}$ on the equatorial positions and $\sim 10^{9} \mathrm{~s}^{-1}$ on the axial position.[47] With high valence state, $\mathrm{V}^{3+}$ and $\mathrm{VO}^{2+}$ can constraint water in its hydration shell strongly enough to overcome the deswelling effect caused by cation uptake, thereby maintaining a higher hydration level in membrane.

\subsection{Influence of vanadium cations on ion transport in the polymer membrane:}

\section{Concentrated Solution Case}

We now turn our attention to the case of VRBs in the context of concentrated solution theory. The results presented here should shed light on interactions of electrolyte solutions with the polymer membranes under conditions that would mimic a more realistic operating battery. In this regime the vanadium $\left(0-2 \mathrm{~mol} \mathrm{dm}^{-3}\right)$ and sulfuric acid $\left(5 \mathrm{~mol} \mathrm{dm}^{-3}\right)$ were concentrated enough to overcome Donnan exclusion, or to achieve socalled Donnan breakthrough, for the anion to enter in significant quantities into the membrane. In contrast to the dilute case, Nafion samples equilibrated in concentrated solutions demonstrate a much less pronounced decrease in conductivity and show similar conductivity at a given vanadium concentration of the bathing electrolyte solutions regardless of the different valence state as shown in Figure 4.

The water and sulfuric acid contents in Nafion equilibrated concentrated electrolyte solutions consistent with vanadium concentration results and are shown in Figure 5 Membrane water and sulfuric acid content are largely controlled by the acid concentration in the electrolyte environment. In dilute electrolyte equilibration, $\mathrm{VO}^{2+}$ and $\mathrm{V}^{3+}$ cannot significantly change water content in membrane. In the concentrated 
electrolyte scenario, the relatively unchanged water and sulfuric acid contents as a function of vanadium concentration suggest that vanadium ions do not affect membrane deswelling in the presence of large amounts of sulfuric acid. This is consistent with the observation on the vanadium concentration's influence on vanadium permeation across Nafion, which we expand upon below. It was illustrated that vanadium permeation, or diffusion, is mainly controlled by the sulfuric acid concentration in the electrolyte [48] (see below). This behavior suggests that equilibration with sulfuric acid is the primary factor determining Nafion water content, consistent with the decreasing water activity with increasing acid concentration and thereby the uptake of electrolyte species and vanadium crossover.

Vanadium ion partitioning in Nafion is highly dependent on the apparent charge number of the cation. The vanadium ion content in Nafion equilibrated in concentrated electrolyte is presented in Figure 6. All three vanadium ion types in Nafion are nearly proportional to vanadium concentration in the electrolyte solutions. $\mathrm{V}^{3+}$ and $\mathrm{VO}^{2+}$ have similar partitioning extent in Nafion, both stronger than $\mathrm{VO}_{2}^{+} \cdot \mathrm{V}^{3+}$ and $\mathrm{VO}^{2+}$ have higher partitioning in Nafion than $\mathrm{VO}_{2}^{+}$because cations with higher valence usually have higher affinity to sulfonate in membrane. $[15,17] \mathrm{V}^{3+}$ and $\mathrm{VO}^{2+}$ have high positive charge to generate stronger electrostatic attraction to sulfonate. Although $\mathrm{VO}^{2+}$ has a lower apparent charge number than $\mathrm{V}^{3+}, \mathrm{VO}^{2+}$ can still have similar affinity to $\mathrm{V}^{3+}$, because it has a vanadium atom with +4 valence in the oxo complex. The affinity of $\mathrm{VO}^{2+}$ for sulfonate may be due to the high positive change on vanadium atom in it. The extent of solvation of the cation and the extent to which the ion's charge is screened also play roles. 
As was the case in dilute solutions, vanadium ions that are partitioned into Nafion from concentrated solutions is the primary reason for the sharp decrease in membrane conductivity. The conductivity of Nafion is highly dependent on the water content given that proton transport is mitigated by water's roles as a mediator.[2, 49-51] The effective proton concentration in the membrane is enhanced by acid dissociation, an effect that is balanced by cations in the membrane reducing the proton concentration and potentially interfering with proton transport.[16, 52] Since the equilibrium in Nafion with concentrated electrolyte solutions includes all these factors (water, acid and cations) the analysis of Nafion conductivity in concentrated electrolyte is complicated and influences the proton mobility and in turn the proton transference number. We can now construct a model to account for these issues.

Because sulfuric acid and sulfonic acid in Nafion can fully dissociate, the charge balance is given by:

$$
n_{\mathrm{H}^{+}}+z_{\mathrm{V}^{\mathrm{x}}+} n_{\mathrm{V}^{\mathrm{x}}}=n_{\mathrm{H}_{2} \mathrm{SO}_{4}}+n_{-\mathrm{SO}_{3} \mathrm{H}}
$$

Vanadium ions in Nafion reduce the number of protons available for charge transport, with a relative proton concentration of $n_{\mathrm{H}^{+}} / n_{-\mathrm{SO}_{3} \mathrm{H}}$. The water content in Nafion equilibrated in the concentrated solutions should be corrected by water in vanadium ion's hydration sphere and extra sulfuric acid. It is assumed that water molecules in the first hydration shell of vanadium ions cannot take part in proton transfer. Water content available for proton transport is reduced: $n_{\mathrm{H}_{2} \mathrm{O}}^{\prime}=n_{\mathrm{H}_{2} \mathrm{O}}-n_{V^{x+}} \times n_{V^{x+}}^{\text {hydration }}$. Here $n_{V^{x+}}^{\text {hydration }}$ is the hydration number of vanadium ions in their first hydration shells; with 
values of 6,5 , and 3 for $\mathrm{V}^{3+}, \mathrm{VO}^{2+}$ and $\mathrm{VO}_{2}^{+}$respectively.[2] Because of high hydrophobicity of bisulfate, we assume water can be similarly coordinated by sulfonate and bisulfate in the ionic domain in membrane. The corrected water content is symbolized as $\lambda^{\prime}$ is given by:

$$
\lambda^{\prime}=\left(\lambda-n_{V^{x+}}^{\text {hydration }} \frac{n_{\mathrm{V}^{\mathrm{x}+}}}{n_{-\mathrm{SO}_{3} \mathrm{H}}}\right) /\left(1+\frac{n_{\mathrm{H}_{2} \mathrm{SO}_{4}}}{n_{-\mathrm{SO}_{3} \mathrm{H}}}\right) .
$$

These results are shown in Figure 7.

In the presence of sulfuric acid, $\mathrm{VO}^{2+}$ and $\mathrm{VO}_{2}^{+}$influence proton transport in Nafion, while $\mathrm{V}^{3+}$ does not interfere with proton mobility. Our modeling analysis was carried out by assuming that proton mobility does not change in the presence of vanadium. It was previously shown that proton mobility is a linear function of water content in Nafion equilibrated with sulfuric acid.[33] Using these assumptions, an empirically derived relationship for the proton mobility's dependence on water content may be given by:

$$
u_{H^{+}}=\left(6.88 \lambda^{\prime}-12.5\right) \times 10^{-5} \mathrm{~cm}^{2} \mathrm{~V}^{-1} \mathrm{~s}^{-1}
$$

The proton transference number can then be calculated by the modeled proton mobility:

$$
t_{H^{+}}=\frac{F c_{H^{+}} u_{H^{+}}}{\sigma_{\text {measured }}}=\frac{F \cdot c_{-\mathrm{SO}_{3} \mathrm{H}} \cdot u_{H^{+}}}{\sigma_{\text {measured }}}\left(\frac{n_{\mathrm{H}^{+}}}{n_{-\mathrm{SO}_{3} \mathrm{H}}}\right)
$$

where $c_{-\mathrm{SO}_{3} \mathrm{H}}$ is the sulfonate concentration in Nafion equilibrated in $5 \mathrm{~mol} \cdot \mathrm{dm}^{-3}$ sulfuric acid solution given by $1.39 \times 10^{-3} \mathrm{~mol} \mathrm{~cm}^{-3}$ according to the Nafion density measurements, 
and is assumed to be constant over the entire vanadium concentration range in the experiment.[33] The calculated proton transference numbers are presented in Figure 8. Clearly, with the no-cation-interference assumption, protons coexisting with $\mathrm{V}^{3+}$ have transference numbers less than one and decrease with increasing acid concentration. This suggests that in the concentrated electrolytes, $\mathrm{V}^{3+}$ in Nafion does not influence proton transfer, similar to that in the dilute electrolyte equilibration case. The $\mathrm{V}^{3+}$ mobility can be calculated, $(6.3 \pm 0.8) \times 10^{-5} \mathrm{~cm}^{2} \mathrm{~V}^{-1} \mathrm{~s}^{-1}$, with the assumption that the anion transference number in Nafion is negligible due to Donnan exclusion.[10, 33, 53] This $\mathrm{V}^{3+}$ mobility is very close to $\mathrm{V}^{3+}$ mobility in the dilute electrolyte equilibration case. However, the proton transference number exceeds unity when protons coexist in the membrane with $\mathrm{VO}^{2+}$ or $\mathrm{VO}_{2}^{+}$. This means that proton mobilities are overestimated with the no-vanadium-interference assumption or that the no-interference assumption is only valid for $\mathrm{V}^{3+}$. Like the $\mathrm{VO}^{2+}$ influence on proton mobility in dilute electrolyte equilibrium[33], $\mathrm{VO}^{2+}$ and $\mathrm{VO}_{2}^{+}$can reduce proton mobility by their presence in Nafion. $\mathrm{VO}_{2}^{+}$has a more significant decelerating effect on proton mobility than $\mathrm{VO}^{2+}$. Since $\mathrm{V}^{3+}$ has the very similar mobility in Nafion equilibrated with dilute or concentrated electrolyte, in this case, we assume that $\mathrm{VO}^{2+}$ has mobility, $6.28 \times 10^{-5} \mathrm{~cm}^{2} \mathrm{~s}^{-1} \mathrm{~V}^{-1}$, identical to its mobility in the dilute electrolyte equilibrated Nafion.

Concerning the mobility of $\mathrm{VO}_{2}^{+}$in Nafion, there is no literature report yet. So we assume that vanadium ions' mobility and diffusivity satisfy Einstein-Smoluchowski equation: $u_{j} \propto\left|z_{j}\right| D_{j}$. The mobility of $\mathrm{VO}_{2}^{+}$can be derived from the diffusivities of vanadium ions 
reported in literature.[22] The derived mobility of $\mathrm{VO}_{2}^{+}$is $3.0 \times 10^{-5} \mathrm{~cm}^{2} \mathrm{~s}^{-1} \mathrm{~V}^{-1}$. Proton mobility can be calculated by the relation between conductivity and mobility:

$$
u_{\mathrm{H}^{+}}=\frac{\left(\sigma-F z_{\mathrm{V}^{x+}} c_{\mathrm{V}^{x+}} u_{\mathrm{V}^{x+}}\right)}{F c_{\mathrm{H}^{+}}}
$$

The calculated proton mobility is dependent on the $\mathrm{VO}^{2+}$ or $\mathrm{VO}_{2}^{+}$content in Nafion, as is presented in Figure 9. Obviously, the decelerating effect of $\mathrm{VO}_{2}^{+}$is stronger than that of $\mathrm{VO}^{2+}$.

In an operating VRFB the driving force for species transport is a gradient in the electrochemical potential [54-56] and multi-component uptake of vanadium species, sulfuric acid, and anions will all have a pronounced effect especially at the higher concentrations that are being sought for grid-scale applications to maximize the volumetric energy density.[1] The models we constructed in this section were limited to "static" observations of how membrane conductivity, ion mobility, species uptake, and proton transference number were affected by acid and vanadium concentrations. An operando analysis of these parameters in working systems would help inform the theory of concentrated solutions for flow batteries and several groups are working towards that end.[57-59] While Nafion has been thoroughly examined in VRFBs due to its high ionic conductivity and chemical stability, the high cost and significant vanadium crossover and key limiting factors to commercial adoption. We suggest that the considerations made above to characterize the effects of species uptake on performance will be of paramount importance.

\subsection{Vanadium permeation through the membrane}


The permeability of the vanadyl ion through Nafion is governed by the partitioning of the ion into the membrane as well as the diffusion coefficient of the ion in the membrane. These two variables are dependent on a number of factors. The partitioning is altered by the acid concentration in the solution around the membrane. As the acid concentration increases, the 'competition' for partitioning favors the protons. Diffusion is also affected by the acid concentration. Water in the membrane acts to form channels through which diffusion occurs, essentially lubricating the diffusion path. With exposure to acid, the membrane dehydrates slowing mobility of all species.[22, 25]

Previous work showed that the membrane permeability decreased dramatically with increasing acid concentration.[25, 60] For a simple experiment in which $\mathrm{VO}^{2+}$ permeation was monitored from a compartment which initially contained $\mathrm{VO}^{2+}$ in acid through the membrane to a compartment that contained only acid, the $\mathrm{VO}^{2+}$ permeation rates depended strongly on exact experimental conditions but were controlled by acid concentration. Increasing the $\mathrm{VO}^{2+}$ concentration while fixing the ratio acid to $\mathrm{VO}^{2+}$ yielded permeation data in which the permeation rate of $\mathrm{VO}^{2+}$ through the membrane decreased with increasing $\left[\mathrm{VO}^{2+}\right]$. In general, over the range of concentration between 0 and $5 \mathrm{M} \mathrm{H}_{2} \mathrm{SO}_{4}$, the permeability of $\mathrm{VO}^{2+}$ dropped by about two orders of magnitude.

Results for similar experiments for $\mathrm{V}^{3+}$, measured using UV-Vis spectroscopy detection[22], and $\mathrm{VO}^{2+}$, measured using EPR detection[48], are summarized in Table 1. Clearly, the permeation rates for the vanadium species are essentially similar and their respective mobilities are very slow relative to that of protons.

\subsection{An Overall Summary of Transport}


Capacity fade that occurs during cycling has been attributed in part to preferential volumetric transfer of vanadium ions and water. Transport of water occurs primarily by diffusion of hydrated species including protons, vanadium ions, sulfate and bisulfate ions, as a result of osmotic pressure differences and by migration of ions with accompanying electroosmotic flow. Using the figures measured or described above, it is possible to assess the relative rates of some of these transport processes that is expected during battery operation.

A calculation of the flux due to permeation as a current density yields $0.7 \times 10^{-4}$ and $2.7 \times 10^{-4} \mathrm{~mA} \mathrm{~cm}^{-2}$ for $\mathrm{V}^{3+}$ and $\mathrm{VO}^{2+}$ respectively. (These correspond to molar fluxes of $\sim 0.7 \times 10^{-9} \mathrm{~mol} \mathrm{~cm}^{-2} \mathrm{sec}^{-1}$ and $\sim 1.4 \times 10^{-9} \mathrm{~mol} \mathrm{~cm}^{-2} \mathrm{sec}^{-1}$ respectively. We note that these current densities are atypical units for fluxes but they provide a simply way to compare fluxes.) Based on the mobilities, the transference number of protons is at least 0.87 and that of each vanadium species roughly 0.065 (assuming that all vanadium species are in the membrane). Thus, the fluxes due to migration at a current density of $100 \mathrm{~mA} \mathrm{~cm}^{-2}$ are orders of magnitude higher than the permeation fluxes. Assuming that the electroosmotic drag coefficient is 3 for protons, 8 for $\mathrm{V}^{3+}$ and 7 for $\mathrm{VO}^{2+}$, the flux of water due to drag in one direction will be on the order of $300 \mathrm{~mA} \mathrm{~cm}^{-2}\left(\sim 3 \times 10^{-6} \mathrm{~mol} \mathrm{~cm}\right.$ ${ }^{2} \mathrm{sec}^{-1}$ ) or roughly 50 times the vanadium flux.

Clearly, the absolute magnitude of these parameters will depend on the exact details of changes of composition during state of charge and thus requires modeling to integrate over these changes. It is useful nonetheless to have a rough idea of how rapidly different transport mechanisms for different species are likely to move those species. 


\section{Conclusions}

We have demonstrated very high performance attainable in some VRFB configurations, with $>2500 \mathrm{~W} \mathrm{~cm}^{-2}$ in an ohmically-limited system. The uptake of ions and water has different character for 'dilute' and 'concentrated' cases, discriminated by whether Donnan exclusion is preserved. In the dilute case, straightforward partitioning, favoring vanadium species over protons, is observed. The conductivity plummets with increasing vanadium uptake in this instance and it appears that the presence of $\mathrm{VO}^{2+}$ affects the proton mobility. Surprisingly, the water content of the membrane does not change strongly with vanadium uptake. In the concentrated case, conductivity decreases much less when vanadium us exchanged into the membrane in contact with concentrated acid. Vanadium uptake corresponds to only about $25 \%$ of the sulfonate sites for $2 \mathrm{M}$ vanadium. The transport of vanadium in permeation experiments is very much controlled by the sulfuric acid concentration as a primary actor. Finally, the rate of vanadium permeation through the membrane is very small relative to the transport rates associated with migration under current. Water is the species moving most rapidly through the membrane when current flows.

The understanding and continued improvement of membranes is critical to improvement in performance of these systems. One area not touched on in this contribution is the urgent need to probe the lifetime of the membrane systems. Some high performance materials have limitations in durability. Developing reliable tests of membrane stability is an absolute necessity for the RFB field. Nonetheless, such materials are still of interest for transport studies to extend our knowledge of the relation 
between structure and properties of the membranes, an area still in its infancy for this type of application.

\section{Acknowledgements}

We gratefully acknowledge the support of this work by the U.S. Department of Energy, Office of Electricity Delivery and Energy Reliability (Dr. Imre Gyuk), by the Office of Naval Research and by the NSF-funded TN-SCORE program, NSF EPS-1004083, under Thrust 2.

\section{Table Captions}

Table 1. Comparison of the mobilities $u_{\mathrm{X}}$ and diffusivities $D_{\mathrm{X}}$ of $\mathrm{V}^{3+}, \mathrm{VO}^{2+}$, and $\mathrm{H}^{+}$in Nafion 117 at $30^{\circ} \mathrm{C}, 5 \mathrm{M}$ acid and $1 \mathrm{M}$ vanadium. $\lambda$ ' is the corrected water content discussed in the text.

\section{Table 1}

\begin{tabular}{|l|c|c|c|}
\hline & $\begin{array}{c}u_{\mathrm{X}}(\text { dilute }) \\
{\left[\mathrm{cm}^{2} \mathrm{~V}^{-1} \mathrm{~s}^{-1}\right]}\end{array}$ & $\begin{array}{c}u_{\mathrm{X}}(\text { concentrated }) \\
{\left[\mathrm{cm}^{2} \mathrm{~V}^{-1} \mathrm{~s}^{-1}\right]}\end{array}$ & $\begin{array}{c}D_{\mathrm{X}} \\
{\left[\mathrm{m}^{2} \mathrm{~s}^{-1}\right]}\end{array}$ \\
\hline $\mathrm{V}^{3+}$ & $6.36 \times 10^{-5}$ & $(6.30 \pm 0.8) \times 10^{-5}$ & $7.12 \times 10^{-13}$ \\
$\mathrm{VO}^{2+}$ & $6.28 \times 10^{-5}$ & $\sim 6.28 \times 10^{-5}$ & $2.69 \times 10^{-12}$ \\
$\mathrm{H}^{+}$ & $8.23 \times 10^{-4}$ & $\left(6.88 \lambda^{\prime}-12.5\right) \times 10^{-5}$ & $3.50 \times 10^{-10}[57]$ \\
\hline
\end{tabular}




\section{Figure captions}

Figure 1. Single-pass discharge polarization curve of a zero-gap VRB comparing the performance of Nafion 212 to SDAPP. HFR denotes the high frequency resistance.

Figure 2. Normalized vanadium content in Nafion 117 with respect to the normalized vanadium concentration in the solution phase.

Figure 3. (a) Comparison between Nafion 117 conductivity loss as a function of vanadium concentration in the equilibrating solution for $\mathrm{H}^{+} / \mathrm{V}^{3+}$ and $\mathrm{H}^{+} / \mathrm{VO}^{2+}$ forms. (b) Comparison between Nafion 117 conductivity loss as a function of vanadium concentration in the membrane for $\mathrm{H}^{+} / \mathrm{V}^{3+}$ and $\mathrm{H}^{+} / \mathrm{VO}^{2+}$ forms.

Figure 4. Nafion conductivity after being equilibrated in electrolyte solutions with vanadium in the $+3,+4$, and +5 valence states. The vanadium ion concentration in solutions was 0 to $2 \mathrm{~mol} \cdot \mathrm{dm}^{-3}$; the total sulfuric acid/bisulfate/sulfate concentration was 5 $\mathrm{mol} \cdot \mathrm{dm}^{-3}$.

Figure 5. Water and sulfuric acid contents in Nafion equilibrated in concentrated electrolyte solutions (vanadium concentrations 0 to $2 \mathrm{~mol} \cdot \mathrm{dm}^{-3}$; total sulfate $5 \mathrm{~mol} \cdot \mathrm{dm}^{-3}$ ). The water and sulfuric acid concentrations are invariant with environmental concentration.

Figure 6. Vanadium ion content in Nafion being equilibrated in concentrated electrolyte solutions with $\mathrm{V}^{3+}, \mathrm{VO}^{2+}$ or $\mathrm{VO}_{2}^{+}$.

Figure 7. Proton content and corrected water content in Nafion after equilibration. The proton is provided by sulfuric and sulfonic acid dissociation and reduced by vanadium replacement. The water content is corrected by vanadium aqua-coordination and extra sulfuric acid.

Figure 8. Proton transference number in Nafion with coexistence of vanadium ions $\left(\mathrm{V}^{3+}\right.$, $\mathrm{VO}^{2+}$ or $\mathrm{VO}_{2}^{+}$) in concentrated electrolyte equilibration. The proton mobility is assumed to be only dependent on membrane's corrected water content.

Figure 9. Calculated proton mobility as a function of vanadium content in Nafion for $\mathrm{VO}^{2+}$ and $\mathrm{VO}_{2}^{+}$. 
Figure 1

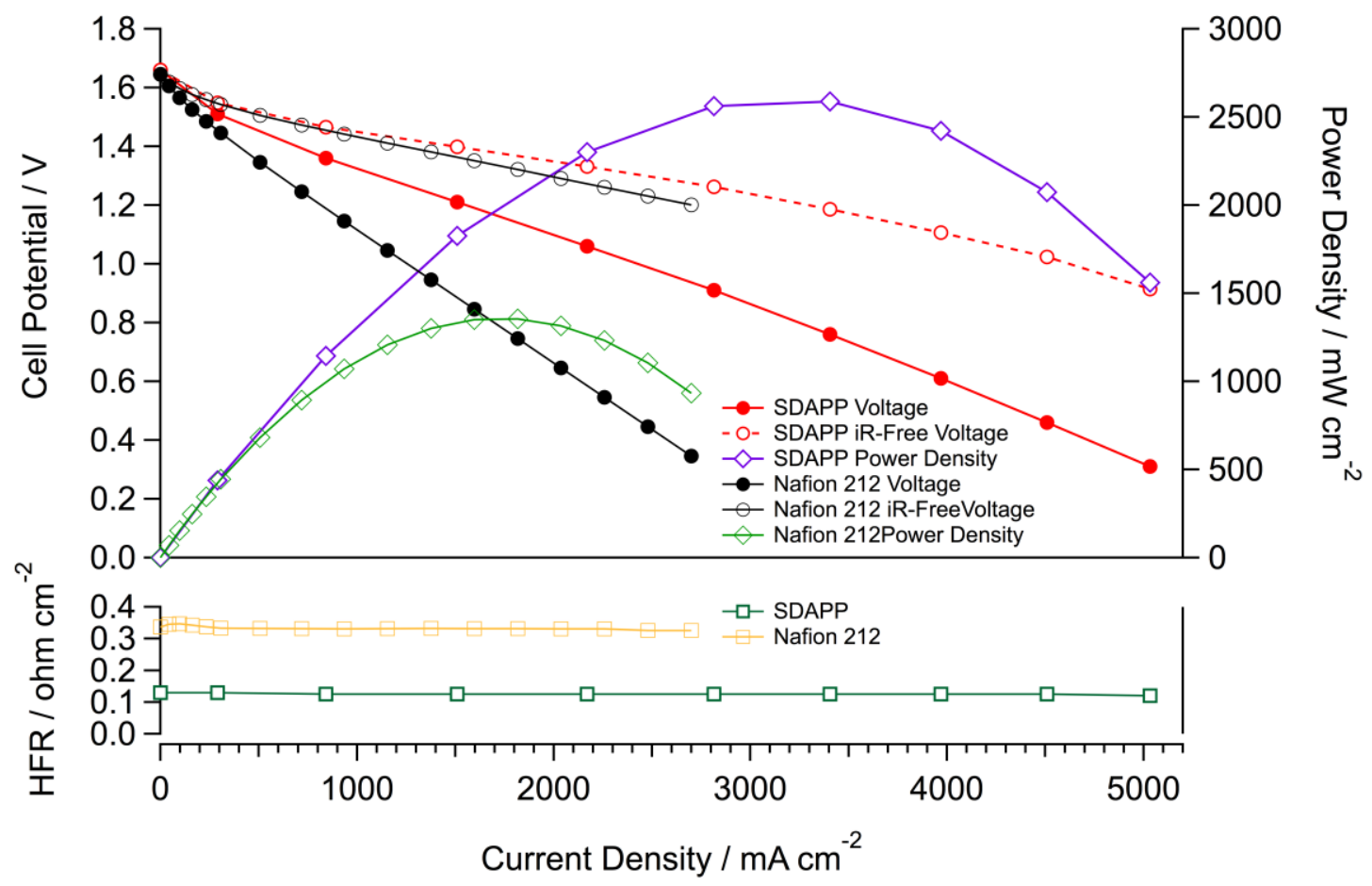


Figure 2

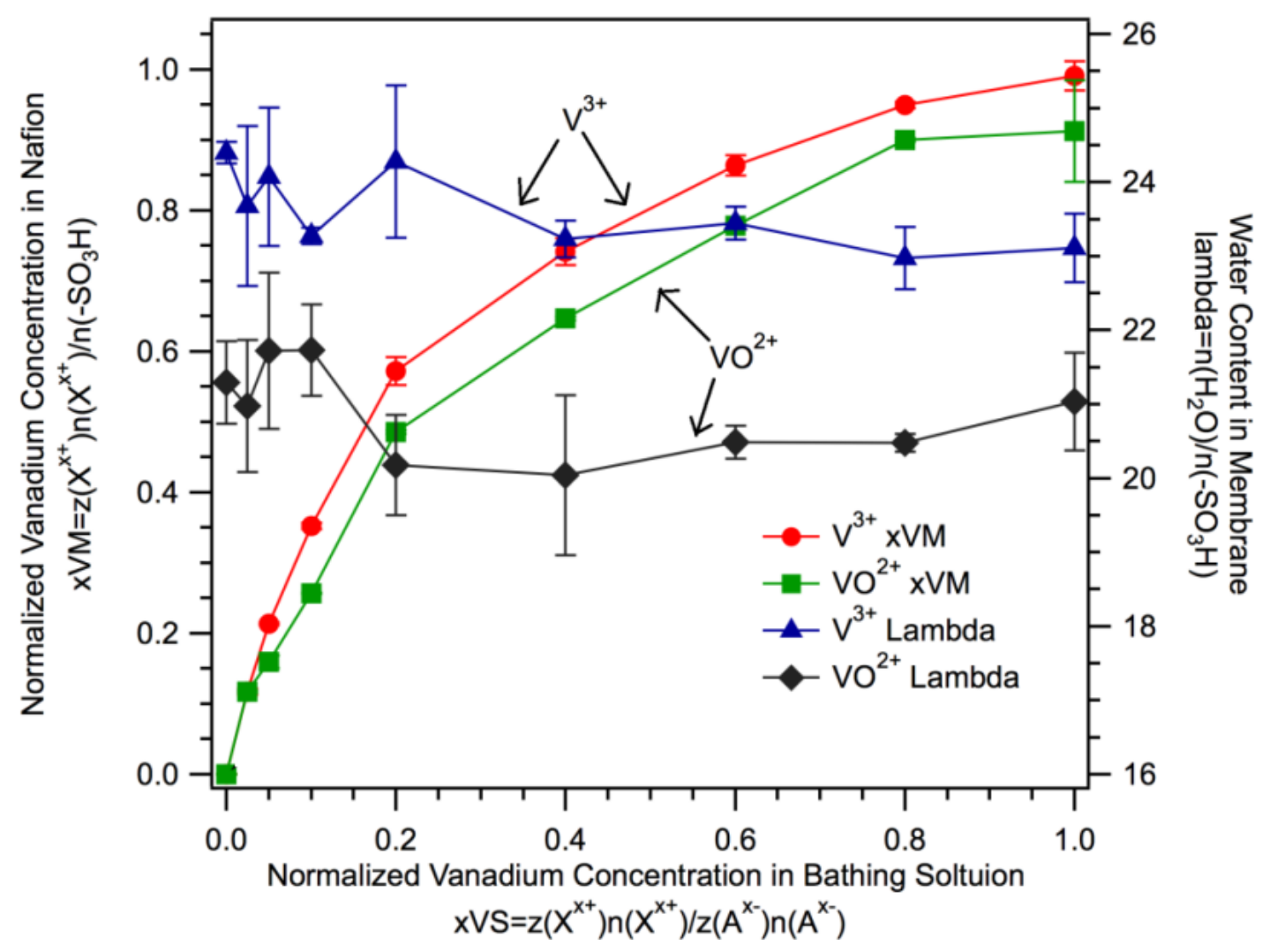


Figure 3

a

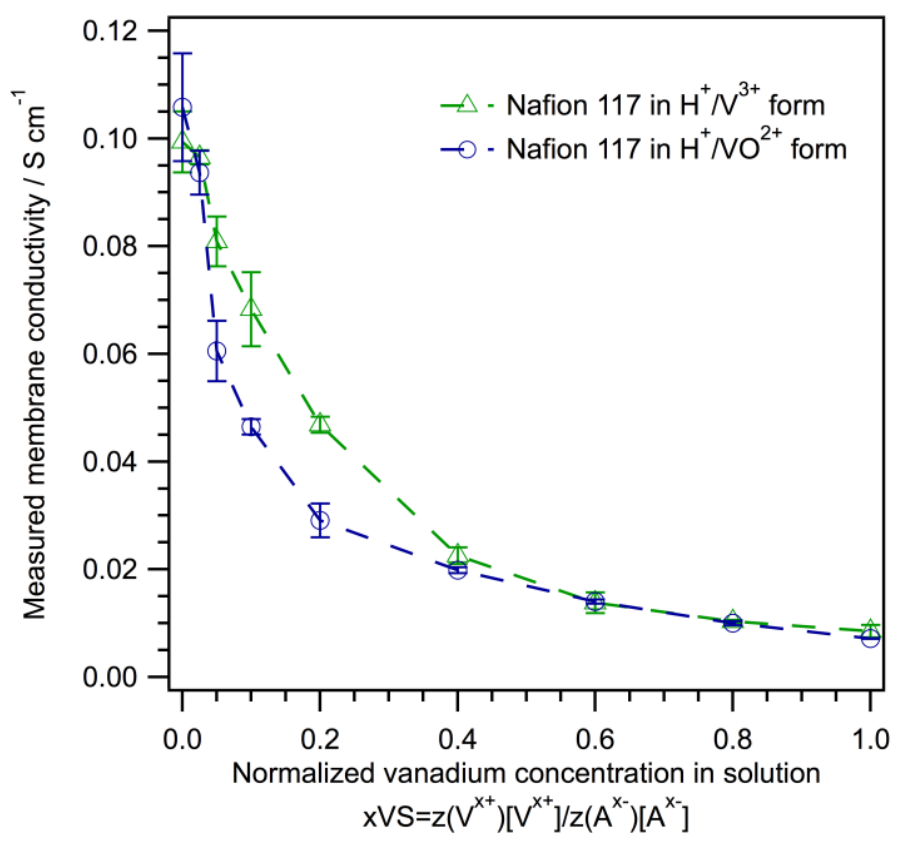

b

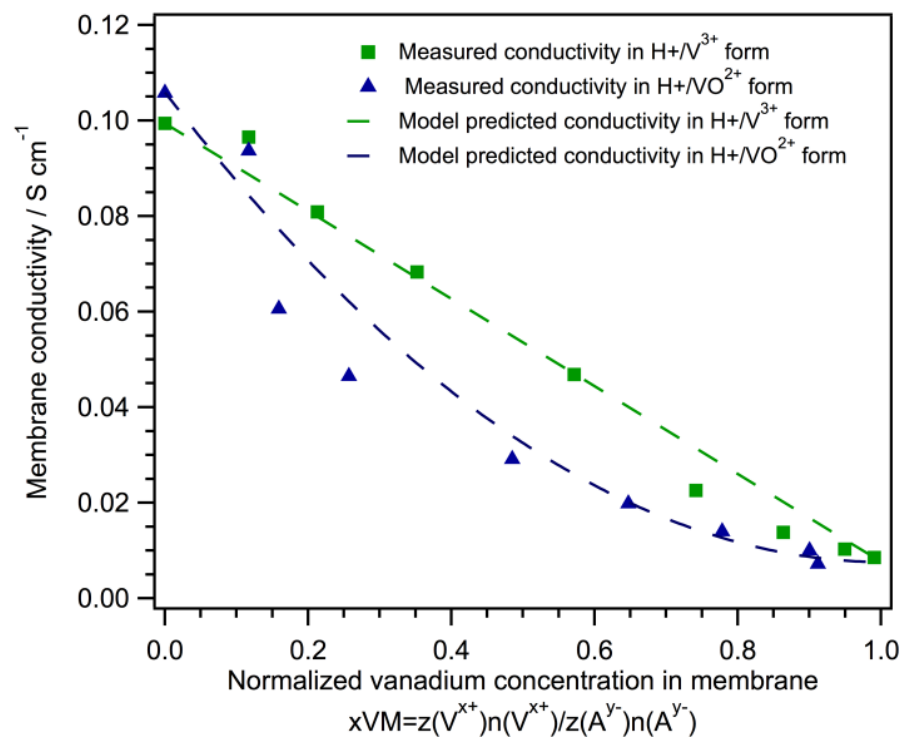


Figure 4

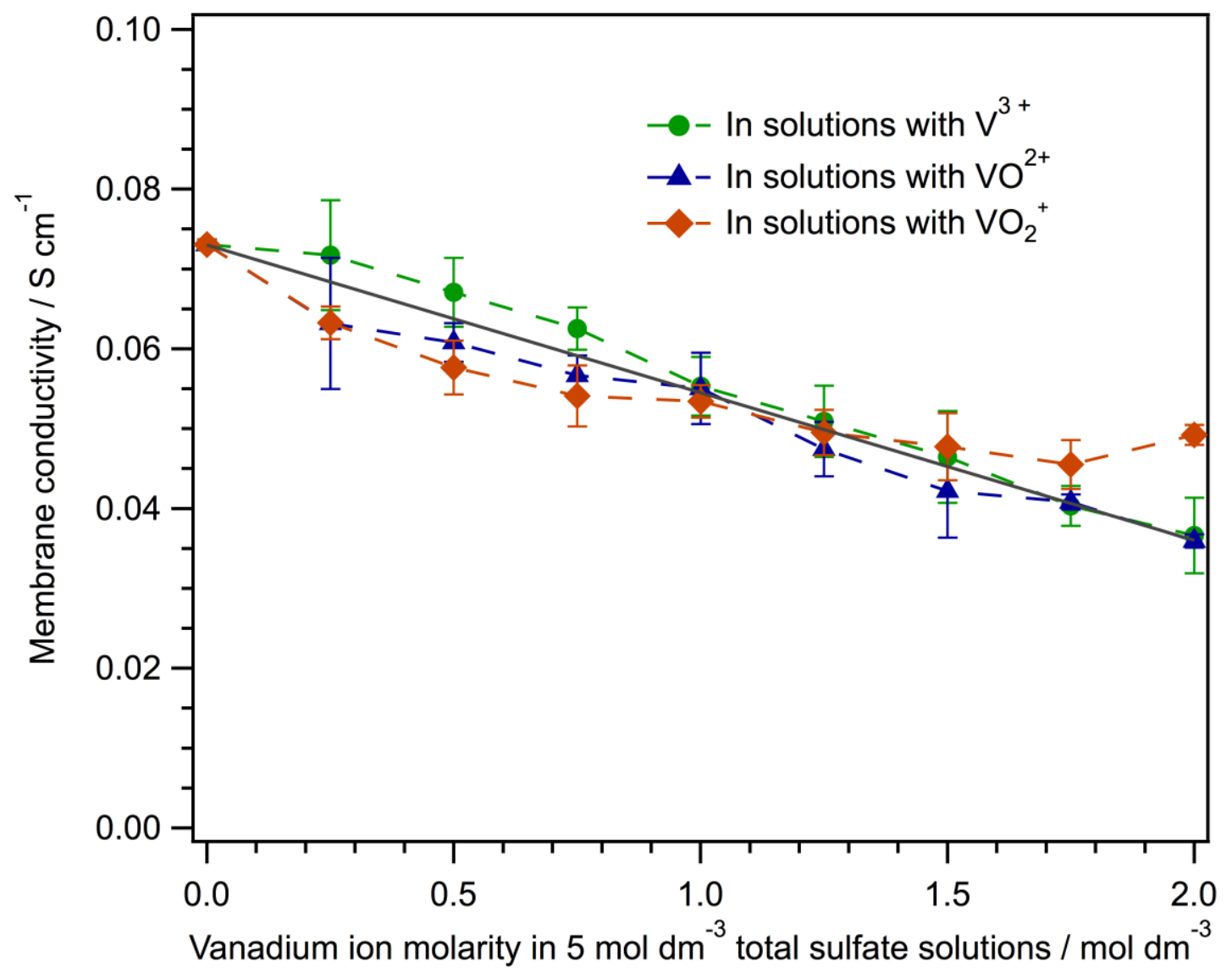


Figure 5

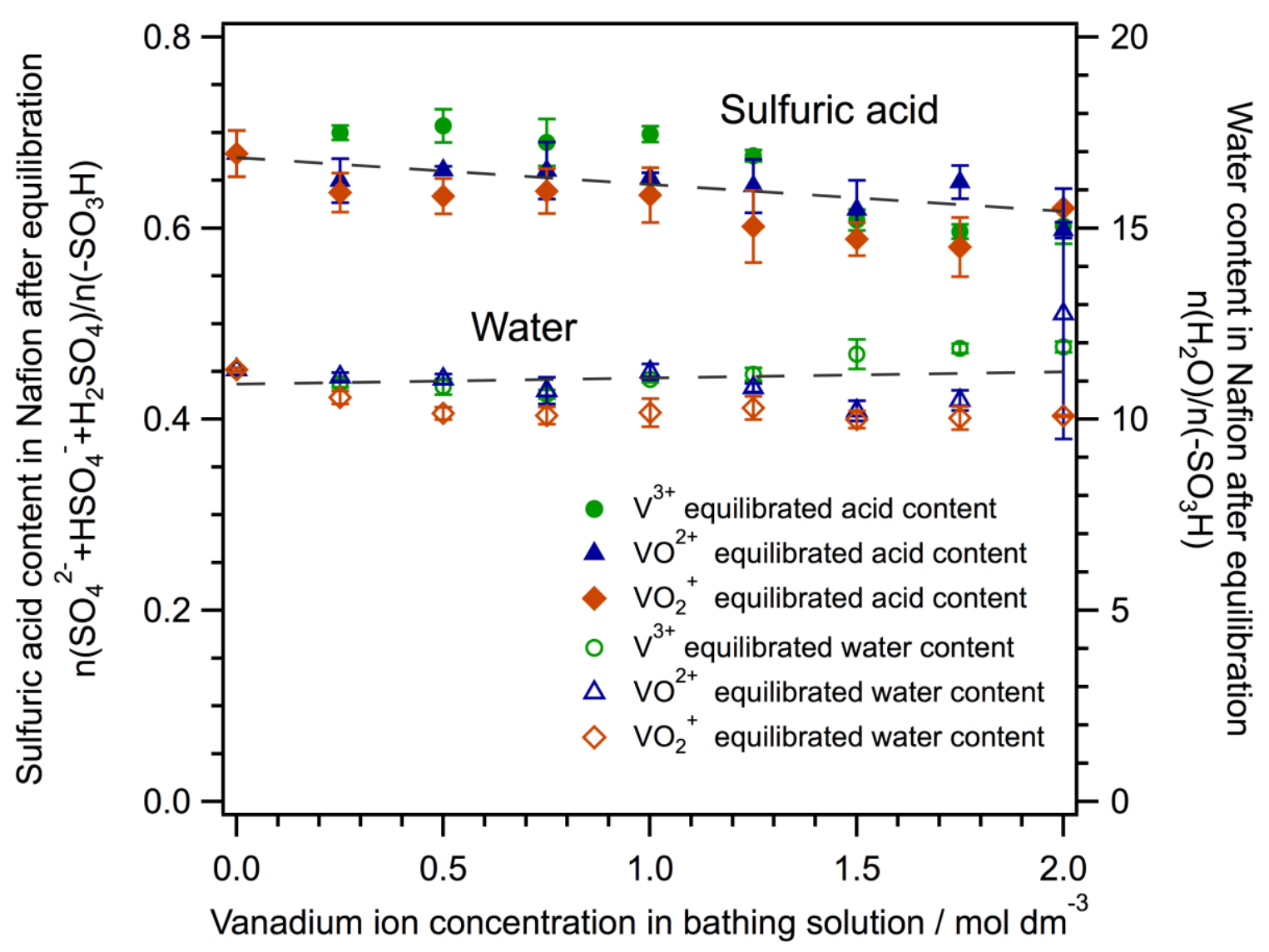


Figure 6

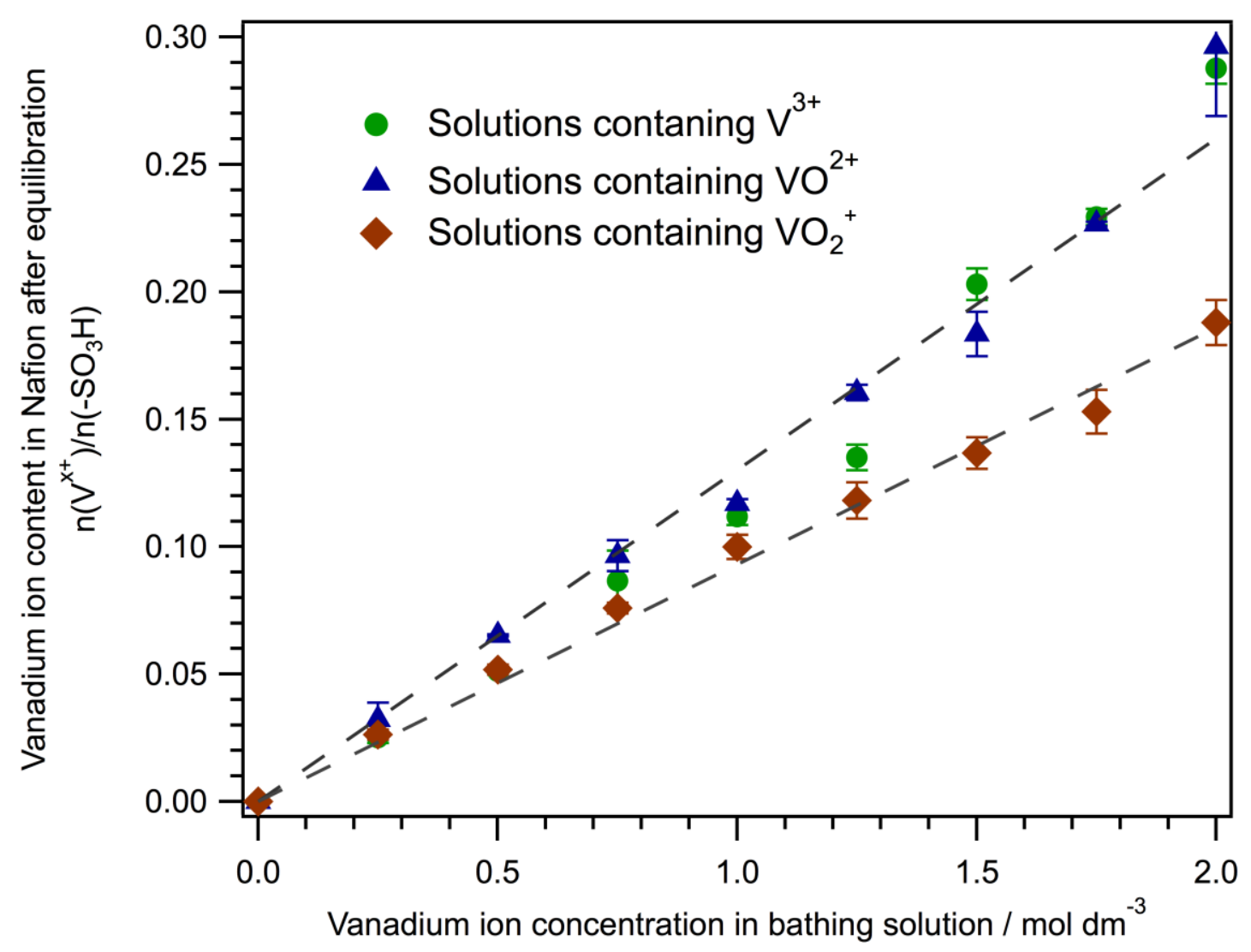


Figure 7

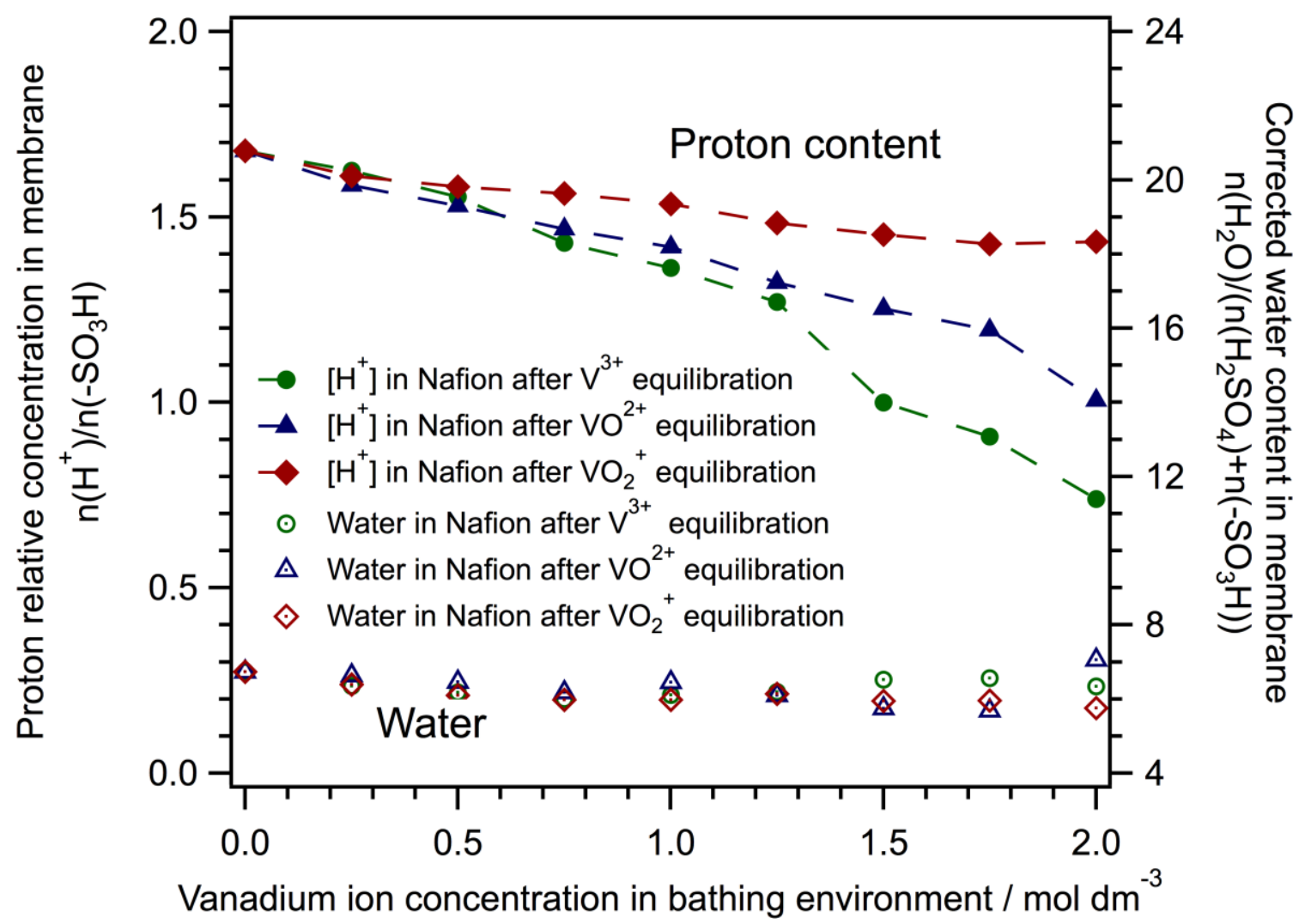


Figure 8

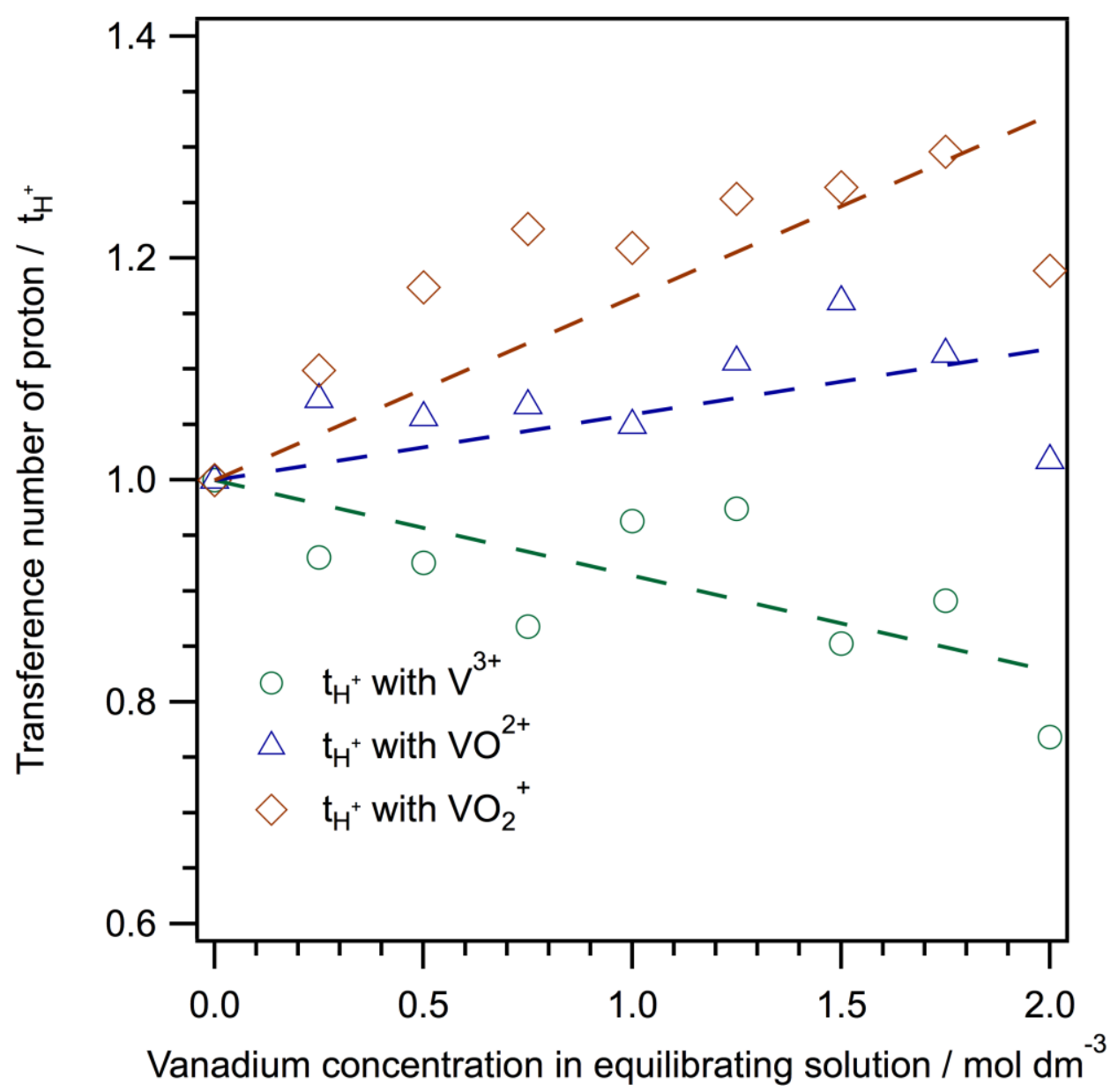


Figure 9

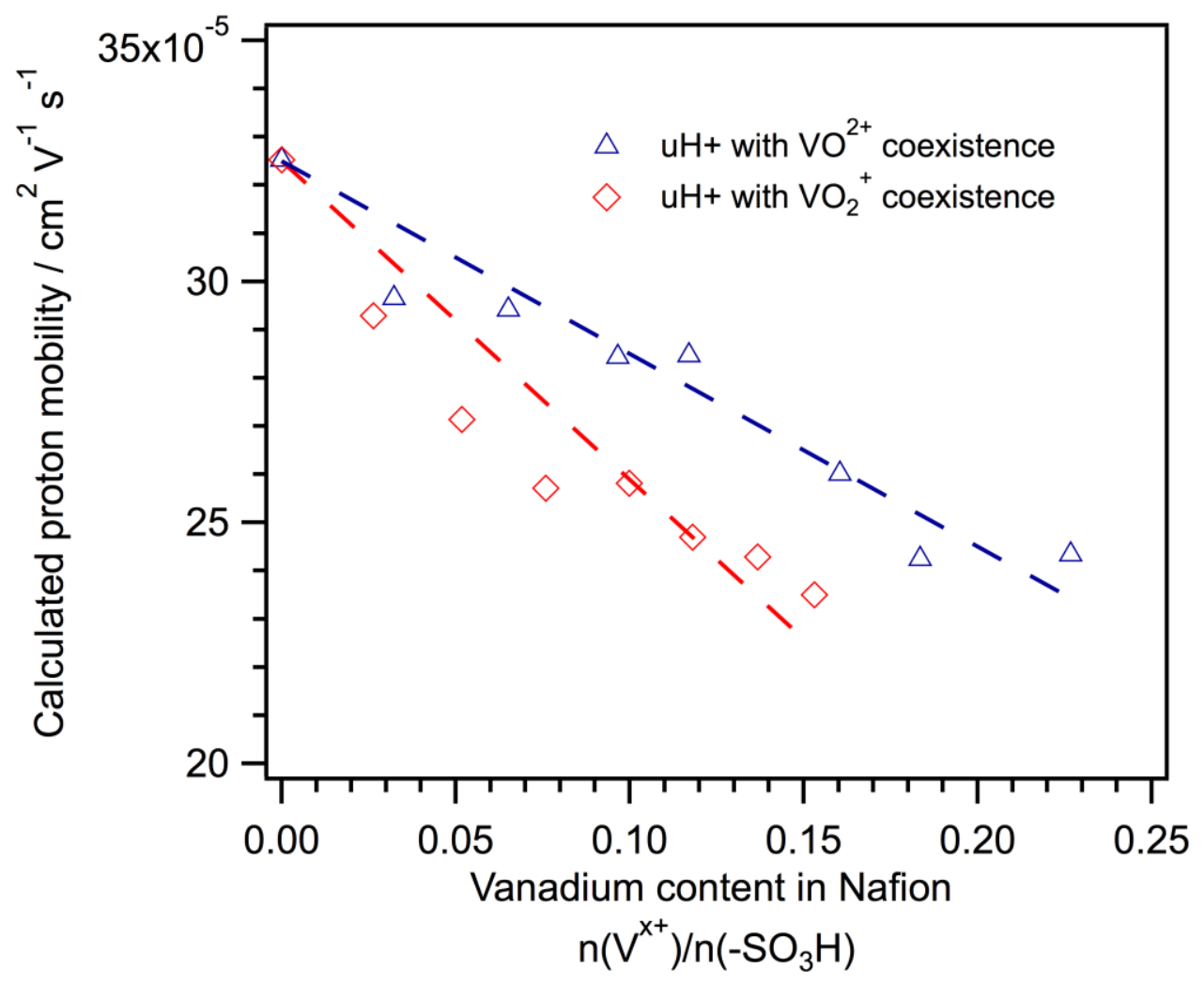




\section{References}

[1] L. Li, S. Kim, W. Wang, M. Vijayakumar, Z. Nie, B. Chen, J. Zhang, G. Xia, J. Hu, G. Graff, J. Liu, Z. Yang, A stable vanadium redox-flow battery with high energy density for large-scale energy storage, Advanced Energy Materials, 1 (2011) 394-400.

[2] M. Vijayakumar, L. Li, G. Graff, J. Liu, H. Zhang, Z. Yang, J.Z. Hu, Towards understanding the poor thermal stability of V5+ electrolyte solution in vanadium redox flow batteries, Journal of Power Sources, 196 (2011) 3669-3672.

[3] M.J. Watt-Smith, H. Al-Fetlawi, P. Ridley, R.G.A. Wills, A.A. Shah, F.C. Walsh, The Importance of Operational Variables, Mathematical Modelling and Electrolyte Monitoring to the Performance of a Vanadium Redox Flow Battery, Journal of Chemical Technology and Biotechnology, 88, (2013), 126-138

[4] Y.P. Ma, M. Doyle, T.F. Fuller, M.M. Doeff, L.C. Dejonghe, J. Newman, The measurement of a complete set of transport-properties for a concentrated solid polymer electrolyte solution, Journal of the Electrochemical Society, 142 (1995) 1859-1868. [5] N.P. Balsara, J. Newman, Relationship between steady-state current in symmetric cells and transference number of electrolytes comprising univalent and multivalent ions, Journal of the Electrochemical Society, 162 (2015) A2720-A2722.

[6] M.W. Verbrugge, R.F. Hill, Experimental and theoretical investigation of perfluorosulfonic acid membranes equilibrated with aqueous sulfuric-acid solutions, Journal of Physical Chemistry, 92 (1988) 6778-6783.

[7] G. Pourcelly, A. Lindheimer, C. Gavach, H.D. Hurwitz, Electrical transport of sulfuric-acid in nafion perfluorosulfonic membranes, Journal of Electroanalytical Chemistry, 305 (1991) 97-113.

[8] B.S. Pivovar, W.H. Smyrl, E.L. Cussler, Electro-osmosis in Nafion 117, polystyrene sulfonic acid, and polybenzimidazole, Journal of the Electrochemical Society, 152 (2005) A53-A60.

[9] T.A. Zawodzinski, C. Derouin, S. Radzinski, R.J. Sherman, V.T. Smith, T.E. Springer, S. Gottesfeld, Water-uptake by and transport through Nafion(r) 117 membranes, Journal of the Electrochemical Society, 140 (1993) 1041-1047.

[10] G. Pourcelly, A. Lindheimer, G. Pamboutzoglou, C. Gavach, Conductivity of sorbed hydrohalogenic acid in nafion perfluorosulfonic membranes, Journal of Electroanalytical Chemistry, 259 (1989) 113-125.

[11] T. Okada, G. Xie, O. Gorseth, S. Kjelstrup, N. Nakamura, T. Arimura, Ion and water transport characteristics of nafion membranes as electrolytes, Electrochimica Acta, 43 (1998) 3741-3747.

[12] A. Kusoglu, K.T. Cho, R.A. Prato, A.Z. Weber, Structural and transport properties of nafion in hydrobromic-acid solutions, Solid State Ionics, 252 (2013) 68-74.

[13] B. Kienitz, B. Pivovar, T. Zawodzinski, F.H. Garzon, Cationic contamination effects on polymer electrolyte membrane fuel cell performance, Journal of the Electrochemical Society, 158 (2011) B1175-B1183.

[14] H.S. Cho, M. Ohashi, J.W. Van Zee, Absorption behavior of vanadium in Nafion (r), Journal of Power Sources, 267 (2014) 547-552. 
[15] T. Okada, Y. Ayato, M. Yuasa, I. Sekine, The effect of impurity cations on the transport characteristics of perfluorosulfonated ionomer membranes, Journal of Physical Chemistry B, 103 (1999) 3315-3322.

[16] T. Okada, N. Nakamura, M. Yuasa, I. Sekine, Ion and water transport characteristics in membranes for polymer electrolyte fuel cells containing $\mathrm{H}+$ and $\mathrm{Ca} 2+$ cations, Journal of the Electrochemical Society, 144 (1997) 2744-2750.

[17] R. Tandon, P.N. Pintauro, Divalent/monovalent cation uptake selectivity in a nafion cation-exchange membrane: Experimental and modeling studies, Journal of Membrane Science, 136 (1997) 207-219.

[18] D.C. Sing, J.P. Meyers, Direct measurement of vanadium crossover in an operating vanadium redox flow battery, ECS Transactions, 50 (2013) 61-72.

[19] K. Knehr, E. Agar, C. Dennison, A. Kalidindi, E. Kumbur, A transient vanadium flow battery model incorporating vanadium crossover and water transport through the membrane, Journal of The Electrochemical Society, 159 (2012) A1446-A1459.

[20] A. Tang, J. Bao, M. Skyllas-Kazacos, Dynamic modelling of the effects of ion diffusion and side reactions on the capacity loss for vanadium redox flow battery, Journal of Power Sources, 196 (2011) 10737-10747.

[21] Y. Zhao, J. Xi, X. Teng, Z. Wu, X. Qiu, Electrolyte volume change study in all vanadium redox flow battery, Acta Chimica Sinica, 69 (2011) 132-136.

[22] C. Sun, J. Chen, H. Zhang, X. Han, Q. Luo, Investigations on transfer of water and vanadium ions across nafion membrane in an operating vanadium redox flow battery, Journal of Power Sources, 195 (2010) 890-897.

[23] C.-H. Wu, H.-Y. Liao, K.-L. Hsueh, J.-S. Hung, Study of the kinetics of vanadium redox reaction by rotating disk electrode, ECS Transactions, 35 (2011) 11-22.

[24] H.-Y. Yang, K.-L. Hsueh, C.-L. Hsieh, J.-S. Hung, Study of the kinetics of vanadium (ii)/(iii) redox reaction, ECS Transactions, 50 (2013) 87-92.

[25] J.S. Lawton, A. Jones, T. Zawodzinski, Concentration dependence of vo2+ crossover of nafion for vanadium redox flow batteries, Journal of The Electrochemical Society, 160 (2013) A697-A702.

[26] F. Rahman;, M. Skylls-Kazacos, Solubility of vanadyl sulfate in concentrated sulfuric acid solutions, J. Power Sources, 72 (1998) 105-110.

[27] A. Tang, S. Ting, J. Bao, M. Skyllas-Kazacos, Thermal modelling and simulation of the all-vanadium redox flow battery, Journal of Power Sources, 203 (2012) 165-176.

[28] M. Skyllas-Kazacos, L. Goh, Modeling of vanadium ion diffusion across the ion exchange membrane in the vanadium redox battery, Journal of Membrane Science, 399 (2012) 43-48.

[29] Q. Luo, L. Li, Z. Nie, W. Wang, X. Wei, B. Li, B. Chen, Z. Yang, In-situ investigation of vanadium ion transport in redox flow battery, Journal of Power Sources, (2012).

[30] S. Slade, S.A. Campbell, T.R. Ralph, F.C. Walsh, Ionic Conductivity of an Extruded Nafion 1100 EW Series of Membranes, Journal of the Electrochemical Society, 149, (2002), A1556-A1564.

[31] S.M. Slade, T.R. Ralph, C. Ponce de León, S.A. Campbell, F.C. Walsh, The Ionic Conductivity of a Nafion ${ }^{\circledR}$ Series of Proton Exchange Membranes Re-cast from Butan-1ol and Propan-2-ol, Fuel Cells, 10, (2010), 567-574. 
[32] D.S. Aaron, Q. Liu, Z. Tang, G.M. Grim, A.B. Papandrew, A. Turhan, T.A. Zawodzinski, M.M. Mench, Dramatic performance gains in vanadium redox flow batteries through modified cell architecture, Journal of Power Sources, 206 (2012) 450453.

[33] Z. Tang, R. Svoboda, J.S. Lawton, D.S. Aaron, A.B. Papandrew, T.A. Zawodzinski, Composition and conductivity of membranes equilibrated with solutions of sulfuric acid and vanadyl sulfate, Journal of the Electrochemical Society, 160 (2013) F1040-F1047. [34] J.-Y. Chen, C.-L. Hsieh, N.-Y. Hsu, Y.-S. Chou, Y.-S. Chen, Determining the limiting current density of vanadium redox flow batteries, Energies, 7 (2014) 5863-5873. [35] Z. Tang, J.S. Lawton, C.-N. Sun, J. Chen, M.I. Bright, A.M. Jones, A.B. Papandrew, C.H. Fujimoto, T.A. Zawodzinski, Characterization of sulfonated diels-alder poly(phenylene) membranes for electrolyte separators in vanadium redox flow batteries, Journal of the Electrochemical Society, 161 (2014) A1860-A1868.

[36] C. Fujimoto, S. Kim, R. Stains, X. Wei, L. Li, Z.G. Yang, Vanadium redox flow battery efficiency and durability studies of sulfonated diels alder poly(phenylene)s, Electrochemistry Communications, 20 (2012) 48-51.

[37] K.L. Huang, T.M. Holsen, J.R. Selman, Impurity partitioning in nafion and ceramic separators used for purification of spent chromium plating solutions, Journal of Membrane Science, 210 (2002) 137-145.

[38] P.N. Pintauro, R. Tandon, L. Chao, W. Xu, R. Evilia, Equilibrium partitioning of monovalent/divalent cation-salt mixtures in nafion cation-exchange membranes, Journal of Physical Chemistry, 99 (1995) 12915-12924.

[39] J. Krakowiak, D. Lundberg, I. Persson, A coordination chemistry study of hydrated and solvated cationic vanadium ions in oxidation states plus III, plus IV, and plus V in solution and solid state, Inorganic Chemistry, 51 (2012) 9598-9609.

[40] M. Saito, N. Arimura, K. Hayamizu, T. Okada, Mechanisms of ion and water transport in perfluorosulfonated ionomer membranes for fuel cells, Journal of Physical Chemistry B, 108 (2004) 16064-16070.

[41] C.J. Ballhausen, H.B. Gray, The electronic structure of the vanadyl ion, Inorganic Chemistry, 1 (1962) 111-122.

[42] J.R. Winkler, H.B. Gray, Electronic structures of oxo-metal ions, in: D.M.P. Mingos, P. Day, J.P. Dahl (Eds.) Molecular electronic structures of transition metal complexes i2012, pp. 17-28.

[43] M. Vijayakumar, L. Li, Z. Nie, Z. Yang, J. Hu, Structure and stability of hexa-aqua $\mathrm{v}($ iii) cations in vanadium redox flow battery electrolytes, Physical Chemistry Chemical Physics, 14 (2012) 10233-10242.

[44] P.A. Bergstrom, J. Lindgren, M. Read, M. Sandstrom, Infrared spectroscopic evidence for second-sphere hydration in aqueous solutions of aluminum(3+), chromium(3+) and rhodium(3+), Journal of Physical Chemistry, 95 (1991) 7650-7655. [45] J. Stangret, T. Gampe, Ionic hydration behavior derived from infrared spectra in hdo, Journal of Physical Chemistry A, 106 (2002) 5393-5402.

[46] I. Waluyo, C. Huang, D. Nordlund, U. Bergmann, T.M. Weiss, L.G.M. Pettersson, A. Nilsson, The structure of water in the hydration shell of cations from x-ray raman and small angle x-ray scattering measurements, Journal of Chemical Physics, 134 (2011). 
[47] E. Wiedemann, A. Heintz, R.N. Lichtenthaler, Transport properties of vanadium ions in cation exchange membranes: Determination of diffusion coefficients using a dialysis cell, Journal of Membrane Science, 141 (1998) 215-221.

[48] J.S. Lawton, D.S. Aaron, Z. Tang, T.A. Zawodzinski, Qualitative behavior of vanadium ions in nafion membranes using electron spin resonance, Journal of Membrane Science, 428 (2013) 38-45.

[49] T.A. Zawodzinski, T.E. Springer, J. Davey, R. Jestel, C. Lopez, J. Valerio, S. Gottesfeld, A comparative study of water uptake by and transport through ionomeric fuel cell membranes, Journal of the Electrochemical Society, 140 (1993) 1981-1985. [50] T.A. Zawodzinski, C. Derouin, S. Radzinski, R.J. Sherman, V.T. Smith, T.E. Springer, S. Gottesfeld, Water uptake by and transport through Nafion 117 membranes, Journal of the Electrochemical Society, 140 (1993) 1041-1047.

[51] M.A. Hickner, Water-mediated transport in ion-containing polymers, Journal of Polymer Science Part B-Polymer Physics, 50 (2012) 9-20.

[52] A. Lehmani, P. Turq, M. Perie, J. Perie, J.P. Simonin, Ion transport in Nafion 117 membrane, Journal of Electroanalytical Chemistry, 428 (1997) 81-89.

[53] G. Pourcelly, A. Lindheimer, C. Gavach, H.D. Hurwitz, Electrical transport of sulphonic acid in nafion perfluorosulphonic membranes, Journal of Electroanalytical Chemistry, 305 (1991) 97-113.

[54] J.P. Meyers, J. Newman, Simulation of the direct methanol fuel cell. II. Modeling and data analysis of transport and kinetic phenomena, Journal of the Electrochemical Society, 149 (2002) A718-A728.

[55] D.C. Sing, P.H. Michael, J.P. Meyers, Redox flow battery simulations for optimizing separator membrane performance, ECS Transactions, 41 (2012) 11-24.

[56] Y.A. Gandomi, T.A. Zawodzinski, M.M. Mench, Concentrated solution model of transport in all vanadium redox flow battery membrane separator, ECS Transactions, 61 (2014) 23-32.

[57] B. Li, Q. Luo, X. Wei, Z. Nie, E. Thomsen, B. Chen, V. Sprenkle, W. Wang, Capacity decay mechanism of microporous separator-based all-vanadium redox flow batteries and its recovery, Chemsuschem, 7 (2014) 577-584.

[58] Y.A. Gandomi, D.S. Aaron, T.A. Zawodzinski, M.M. Mench, In situ potential distribution measurement and validated model for all-vanadium redox flow battery, Journal of the Electrochemical Society, 163 (2016) A5188-A5201.

[59] Z.-Z. Lu, S.-L. Hu, X.-L. Luo, Z.-H. Wu, L.-Q. Chen, X.-P. Qiu, Effects of proton exchange membranes on performance of vanadium redox flow battery, Chemical Journal of Chinese Universities-Chinese, 28 (2007) 145-148.

[60] M.W. Verbrugge, R.F. Hill, Ion and solvent transport in ion-exchange membranes II . A radiotracer study of the sulfuric acid, Nafion 117 system, Journal of the Electrochemical Society, 137 (1990) 893-899. 